\title{
Development of a new semi-empirical parameterization for below-cloud scavenging of size-resolved aerosol particles by both rain and snow
}

\author{
X. Wang ${ }^{1}$, L. Zhang ${ }^{2}$, and M. D. Moran ${ }^{2}$ \\ ${ }^{1}$ Kellys Environmental Services, Toronto, Ontario, Canada \\ ${ }^{2}$ Air Quality Research Division, Science and Technology Branch, Environment Canada, 4905 Dufferin St, Toronto, Ontario, \\ M3H 5T4, Canada \\ Correspondence to: L. Zhang (leiming.zhang@ec.gc.ca)
}

Received: 27 October 2013 - Published in Geosci. Model Dev. Discuss.: 27 November 2013

Revised: 21 March 2014 - Accepted: 21 March 2014 - Published: 12 May 2014

\begin{abstract}
A parameter called the scavenging coefficient $\Lambda$ is widely used in aerosol chemical transport models (CTMs) to describe below-cloud scavenging of aerosol particles by rain and snow. However, uncertainties associated with available size-resolved theoretical formulations for $\Lambda$ span one to two orders of magnitude for rain scavenging and nearly three orders of magnitude for snow scavenging. Two recent reviews of below-cloud scavenging of size-resolved particles recommended that the upper range of the available theoretical formulations for $\Lambda$ should be used in CTMs based on uncertainty analyses and comparison with limited field experiments. Following this recommended approach, a new semiempirical parameterization for size-resolved $\Lambda$ has been developed for below-cloud scavenging of atmospheric aerosol particles by both rain $\left(\Lambda_{\text {rain }}\right)$ and snow $\left(\Lambda_{\text {snow }}\right)$. The new parameterization is based on the 90th percentile of $\Lambda$ values from an ensemble data set calculated using all possible "realizations" of available theoretical $\Lambda$ formulas and covering a large range of aerosol particle sizes and precipitation intensities $(R)$. For any aerosol particle size of diameter $d$, a strong linear relationship between the 90th-percentile $\log _{10}(\Lambda)$ and $\log _{10}(R)$, which is equivalent to a power-law relationship between $\Lambda$ and $R$, is identified. The log-linear relationship, which is characterized by two parameters (slope and $y$ intercept), is then further parameterized by fitting these two parameters as polynomial functions of aerosol size $d$. A comparison of the new parameterization with limited measurements in the literature in terms of the magnitude of $\Lambda$ and the relative magnitudes of $\Lambda_{\text {rain }}$ and $\Lambda_{\text {snow }}$ suggests that it
\end{abstract}

is a reasonable approximation. Advantages of this new semiempirical parameterization compared to traditional theoretical formulations for $\Lambda$ include its applicability to belowcloud scavenging by both rain and snow over a wide range of particle sizes and precipitation intensities, ease of implementation in any CTM with a representation of size-distributed particulate matter, and a known representativeness, based on the consideration in its development, of all available theoretical formulations and field-derived estimates for $\Lambda(d)$ and their associated uncertainties.

\section{Introduction}

The removal of below-cloud aerosol particles by precipitation, either rain or snow, decreases the concentrations of particulate matter in the air and contributes to the wet deposition of toxic pollutants. This process has been identified as one of the most efficient removal mechanisms for atmospheric particles and is thus a key process in aerosol chemical transport models (CTMs) (Textor et al., 2006). Simulating this process with reasonable accuracy in CTMs has important impacts when model results from CTMs are used to assess air quality, climate, or ecosystem issues. This process, however, involves complex interactions between aerosol particles and falling hydrometeors and thus is commonly parameterized in CTMs (e.g., Zhang, 2008; Gong et al., 2011). A parameter called the scavenging coefficient $\Lambda\left(\mathrm{s}^{-1}\right)$ serves this purpose (Seinfeld and Pandis, 2006). 
Various theoretical and empirical formulations for $\Lambda$ exist in the literature to parameterize rain and snow scavenging of below-cloud aerosol particles. This choice matters because CTMs with different $\Lambda$ formulations produce significantly different predictions of particulate matter concentrations and atmospheric deposition budgets (e.g., Rasch et al., 2000; Solazzo et al., 2012). To quantify the differences in the existing size-resolved formulations for $\Lambda$ and to identify the dominant product terms causing these differences, we recently conducted detailed reviews of available parameterizations of below-cloud scavenging of size-resolved aerosol particles by rain $\left(\Lambda_{\text {rain }}\right)$ and by snow $\left(\Lambda_{\text {snow }}\right)$ (Wang et al., 2010, 2011; Zhang et al., 2013). The major conclusions from these review studies can be summarized as follows:

1. Different theoretical formulations for $\Lambda$ can differ by one to two orders of magnitude for scavenging by rain ( $\left.\Lambda_{\text {rain }}\right)$ and by up to three orders of magnitude for scavenging by snow $\left(\Lambda_{\text {snow }}\right)$, depending on aerosol particle size.

2. Different formulas for hydrometeor-aerosol particle collection efficiency, which is one of the key product terms of the available theoretical formulations for $\Lambda$, can cause uncertainties of one order of magnitude or more for both $\Lambda_{\text {rain }}$ and $\Lambda_{\text {snow, }}$, whereas different formulas for the three other product terms of $\Lambda$, that is, the number size distribution, terminal velocity, and effective cross-sectional area of falling hydrometeors, can cause uncertainties of a factor of 2 to 5 in $\Lambda$.

3. The majority of field-derived estimates of $\Lambda_{\text {rain }}$, from which empirical $\Lambda_{\text {rain }}$ formulas were developed, are one to two orders of magnitude larger than all theoretical $\Lambda_{\text {rain }}$ formulas; the only exception is one controlled outdoor field experiment that obtained $\Lambda_{\text {rain }}$ to a similar order of magnitude to the theoretical values (Sparmacher et al., 1993; Wang et al., 2010). A similar feature was also found for $\Lambda_{\text {snow }}$, although the differences between the few available field measurements and theoretical values are not as large as for $\Lambda_{\text {rain }}$.

4. The differences between empirical and theoretical $\Lambda$ values can largely be explained by additional processes/mechanisms that influence field-derived estimates of $\Lambda$ but that are not considered in the theoretical $\Lambda$ formulas.

Based on the conclusions listed above, we provided some recommendations regarding the applications of $\Lambda_{\text {rain }}$ and $\Lambda_{\text {snow }}$ parameterizations in CTMs (Wang et al., 2010, 2011; Zhang et al., 2013) as follows:

1. Empirical $\Lambda$ formulas should not be used in CTMs because some of the processes contributing to the fieldderived estimates of $\Lambda$ are treated in CTMs separately.
2. Upper-range values of available theoretical $\Lambda$ formulations should be used in CTMs because they are closer to, while still smaller than, the field-derived estimates of $\Lambda$, and thus are thought to be more realistic than mid- to lower range values from the available theoretical $\Lambda$ formulations.

3. A simple semi-empirical formula for size-resolved $\Lambda_{\text {rain }}$ and $\Lambda_{\text {snow }}$ should be developed that takes into account the large range of $\Lambda_{\text {rain }}$ and $\Lambda_{\text {snow }}$ values that can be obtained from existing theoretical formulas, the many different possible choices for their product terms, and the upper-bound values provided by fieldderived estimates. Note that certain physical processes that have potential to increase particle collection efficiency, for example, storm dynamics (Chate, 2005) and rear capture of particles by falling drops (Quérel et al., 2013), are not explicitly or implicitly treated in any existing theoretical formulas. Thus, existing theoretical formulas are likely to be biased low for certain rain types.

The present study follows the above recommendations to develop a new semi-empirical formula for size-resolved $\Lambda_{\text {rain }}$ and $\Lambda_{\text {snow }}$. The new parameterization is based on the existing theoretical framework for $\Lambda_{\text {rain }}$ and $\Lambda_{\text {snow }}$ (e.g., Slinn, 1984). Existing empirical $\Lambda_{\text {rain }}$ and $\Lambda_{\text {snow }}$ formulas purely based on field measurements are not used directly for the parameterization development; they are, however, used for comparison, selection, and evaluation purposes in this study. In the following sections, the methodology employed to develop the new parameterization is briefly described in Sect. 2. The development and resulting form of the parameterization is described in detail in Sect. 3. Next, a discussion on the new parameterization is presented in Sect. 4 followed by some conclusions in Sect. 5.

\section{Methodology}

In CTMs that simulate aerosol particle number concentrations, the time change of number concentration for aerosol particles undergoing below-cloud scavenging by falling hydrometeors is commonly described as (Seinfeld and Pandis, 2006)

$\frac{\partial n(d, t)}{\partial t}=-\Lambda(d) \cdot n(d, t)$,

where $n(d, t)$ is the number concentration of aerosol particles with a diameter $d$ at time $t$ and $\Lambda(d)$ is the size-resolved scavenging coefficient $\left(\mathrm{s}^{-1}\right)$ for aerosol particles of size $d$. $\Lambda(d)$ can be described theoretically as (Slinn, 1984)

$\Lambda(d)=\int_{0}^{\infty} A\left(d, D_{\mathrm{p}}\right)\left(V_{D}-v_{d}\right) E\left(d, D_{\mathrm{p}}\right) N\left(D_{\mathrm{p}}\right) \mathrm{d} D_{\mathrm{p}}$, 
where $D_{\mathrm{p}}$ is the diameter of a hydrometeor (either raindrop or melted snow particle) and $N\left(D_{\mathrm{p}}\right)$ is the number size distribution of hydrometeors, $V_{D}$ and $v_{d}$ are the terminal velocities of hydrometeors and aerosol particles, respectively, $E\left(d, D_{\mathrm{p}}\right)$ is the collection efficiency (dimensionless) between an aerosol particle of size $d$ and a hydrometeor of size $D_{\mathrm{p}}$, and $A\left(d, D_{\mathrm{p}}\right)$ is the effective cross-sectional area of a hydrometeor projected normal to the fall direction.

According to Eq. (2), if it is assumed that $V_{D} \gg v_{d}$, then calculating $\Lambda$ requires knowledge of four product terms: $E\left(d, D_{\mathrm{p}}\right), N\left(D_{\mathrm{p}}\right), V_{D}$, and $A$. Since raindrops are usually assumed to be spherical, the effective cross-sectional area $A$ of a falling raindrop can be estimated as (e.g., Slinn, 1984)

$A\left(d, D_{\mathrm{p}}\right)=\frac{\pi}{4}\left(D_{\mathrm{p}}+d\right)^{2}$.

Extending the review of Wang et al. (2010), lists and references of available formulas for the other three product terms for the calculation of $\Lambda_{\text {rain }}$ are provided in Tables 1,2, and 3 , respectively, while lists and references of available formulas for all four product terms for the calculation of $\Lambda_{\text {snow }}$ are provided in Tables 4, 5, 6, and 7, respectively (Zhang et al., 2013). All symbols used in this study are defined in the appendices in Table E1 (in Appendix E).

As mentioned in the Introduction, different choices for these product terms give a large range of $\Lambda$ values. To develop a new $\Lambda$ parameterization, the following five-step approach was employed. The first step was to generate an ensemble of all potential $\Lambda_{\text {rain }}$ values as a function of aerosol particle diameter $d$ and a specified precipitation intensity $R$ using all possible combinations of the product-term formulas listed in Tables 1-3, and to generate a second ensemble of all potential $\Lambda_{\text {snow }}$ values using all possible combinations of the product-term formulas listed in Tables 4-7. In the second step, the ensembles of calculated $\Lambda_{\text {rain }}$ and $\Lambda_{\text {snow }}$ values were closely scrutinized and unrealistic values were modified or removed where it was possible to identify shortcomings in the formulation of any of the product-term parameterizations. In the third step, the 90th-percentile values of $\Lambda_{\text {rain }}$ and $\Lambda_{\text {snow }}$ were extracted from the reduced ensembles of $\Lambda_{\text {rain }}$ and $\Lambda_{\text {snow }}$ values for each aerosol particle diameter bin and precipitation intensity $R$. Note that the decision to choose 90th-percentile values was somewhat arbitrary, but it was based on the recommendations in Wang et al. (2010) and Zhang et al. (2013) that the upper range of theoretical $\Lambda_{\text {rain }}$ and $\Lambda_{\text {snow }}$ values should be used in CTMs and on the complementary evidence on upper bounds provided by field-derived estimates of $\Lambda_{\text {rain }}$ and $\Lambda_{\text {snow. }}$. Steps 1-3 were repeated many times in order to span a large range of precipitation intensity values, which resulted in a large data set of 90th-percentile $\Lambda_{\text {rain }}(d, R)$ and $\Lambda_{\text {snow }}(d, R)$ values. This 90th-percentile data set was then used as the basis for generating the new $\Lambda_{\text {rain }}$ and $\Lambda_{\text {snow }}$ parameterizations through a curve-fitting technique (step 4) followed by an assessment of their relative errors (step 5). The next section describes the application of the above approach to develop a new parameterization for the below-cloud scavenging of size-resolved aerosol particles by both rain and snow.

\section{Development of the new parameterization}

To solve Eq. (2) numerically for size-resolved $\Lambda$ using selected product-term formulas, a number of size bins or sections need to be defined to describe both aerosol-particle and hydrometeor size distributions. A similar bin structure to that used previously in Wang et al. (2010) and Zhang et al. (2013) was also used here. Briefly, one set of 100 size bins was used to discretize the size distribution of raindrops (for $\Lambda_{\text {rain }}$ ) or snow particles (for $\Lambda_{\text {snow }}$ ) and a second set of 100 size bins was used to discretize the size distribution of aerosol particles. The size ranges considered were $1 \mu \mathrm{m}$ to $10 \mathrm{~mm}$ in particle diameter for raindrops or snow particles (as liquidwater equivalent) and 0.001 to $100 \mu \mathrm{m}$ in particle diameter for aerosol particles. A constant-volume ratio between successive size bins was used for both discretizations. The ambient temperature was assumed to be $15^{\circ} \mathrm{C}$ for rain cases and $-10^{\circ} \mathrm{C}$ for snow cases and the ambient pressure was assumed to be $1013.5 \mathrm{hPa}$. Uncertainties associated with the choice of ambient temperature and pressure values are discussed in Sect. 4.3 below.

\section{1 $\Lambda_{\text {rain }}$}

Following step 1 of the approach described in Sect. 2, we calculated $\Lambda_{\text {rain }}$ as a function of particle diameter for 100 size bins using Eq. (2) and 400 different combinations of formulas for $E\left(d, D_{\mathrm{p}}\right), N\left(D_{\mathrm{p}}\right)$, and $V_{D}$ (i.e., 5,10 , and 8 formulas, respectively, as listed in Tables 1,2 , and 3). Note that the product-term formulas were originally generated from a wide range of rain types such as "widespread", convective, thunderstorm, and hurricane. Figure 1 shows the results for a precipitation intensity $R$ of $1.0 \mathrm{~mm} \mathrm{~h}^{-1}$ as an example. The predicted $\Lambda_{\text {rain }}$ values differ by one order of magnitude for ultrafine (e.g., $<0.01 \mu \mathrm{m}$ ) and giant (e.g., $>10 \mu \mathrm{m}$ ) aerosol particles and by nearly two orders of magnitude for particles in the diameter range from 0.01 to $10 \mu \mathrm{m}$.

Next, following step 2 from Sect. 2, we found that two groups of $\Lambda_{\text {rain }}$ profiles had different shapes from the rest of the profiles for all of the precipitation intensities considered in this study. One group predicts much higher $\Lambda_{\text {rain }}$ values for aerosol particles larger than $0.5 \mu \mathrm{m}$ (see group of yellow lines in Fig. 1a) and the other group predicts much lower $\Lambda_{\text {rain }}$ values for aerosol particles larger than $1.0 \mu \mathrm{m}$ (see group of red lines in Fig. 1a). The first group was identified to be caused by the use of the $E\left(d, D_{\mathrm{p}}\right)$ formula of Park et al. (2005) and the second group by the use of the $E\left(d, D_{\mathrm{p}}\right)$ scheme of Ackerman et al. (1995).

Upon further investigation we found that the Park et al. (2005) formula neglects the critical Stokes number 
Table 1. List of semi-empirical formulas for raindrop-aerosol particle collection efficiency $E\left(d, D_{\mathrm{p}}\right)$. Symbols used in Tables $1-9$ and their units are defined in Table E1 in Appendix E.

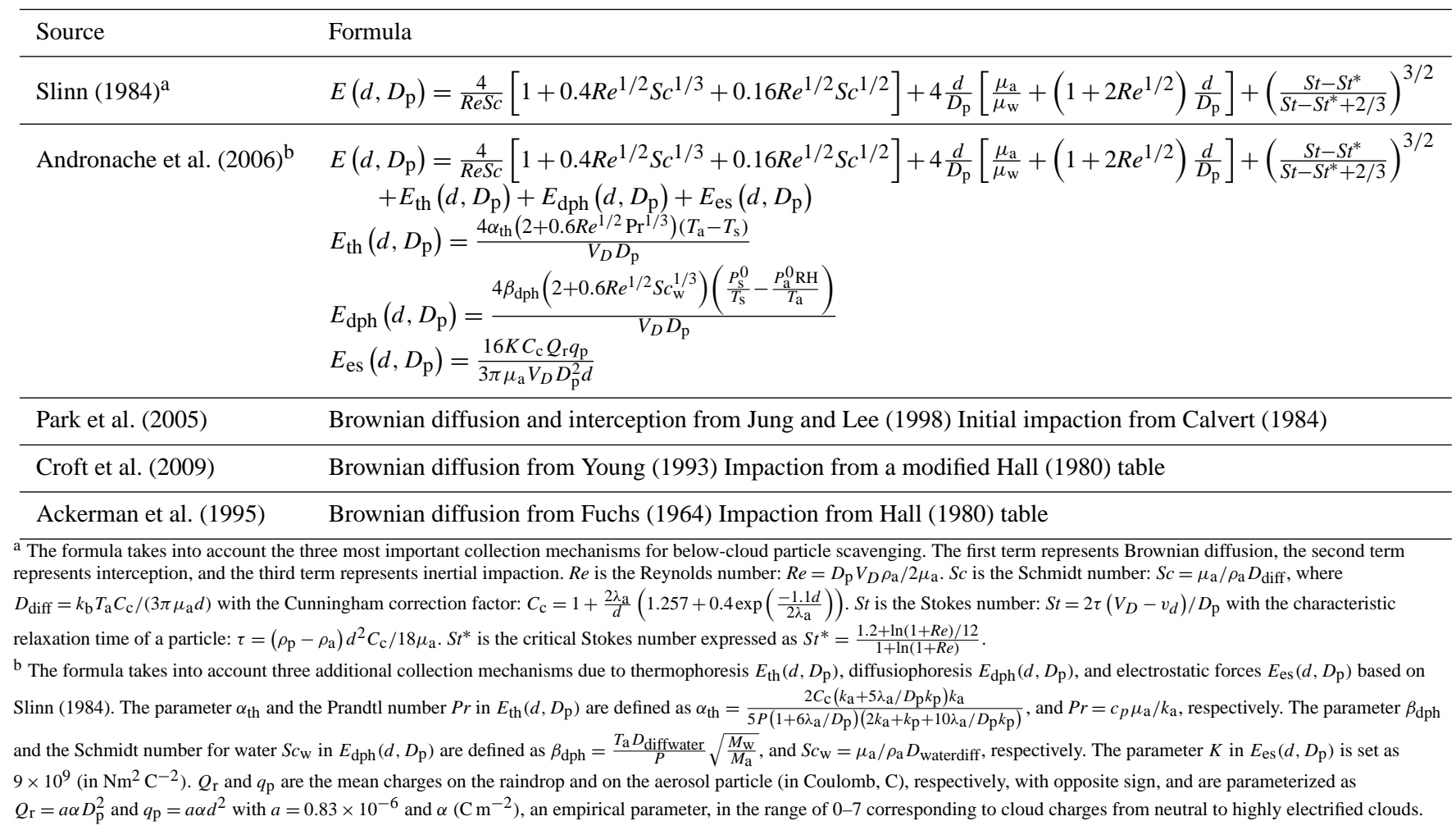

threshold in the inertial impaction mechanism, which leads to an additional contribution of inertial impaction to $E\left(d, D_{\mathrm{p}}\right)$ for particles smaller than $3 \mu \mathrm{m}$ in diameter. In fact, inertial impaction can only occur for particles with a Stokes number above the critical Stokes number, which is close to 1.2. The corresponding threshold diameter is close to $3 \mu \mathrm{m}$ for a unit-density particle and a $1 \mathrm{~mm}$ raindrop (Phillips and Kaye, 1999; Loosmore and Cederwall, 2004). Thus, $\Lambda_{\text {rain }}$ calculated using the $E\left(d, D_{\mathrm{p}}\right)$ formula of Park et al. (2005) is believed to be an overestimation for particles with diameters from 0.5 to $3 \mu \mathrm{m}$. The $E\left(d, D_{\mathrm{p}}\right)$ scheme of Ackerman et al. (1995), on the other hand, considers the collection mechanisms of Brownian diffusion, convective Brownian diffusion enhancement, and inertial impaction. In this scheme, the required collision efficiency values are interpolated from a look-up table from Hall (1980). The table, however, only covers collector (raindrop) sizes of $10-300 \mu \mathrm{m}$ in radius colliding with aerosol particles (collected particles) with size ratios (the so-called p-ratio) from 0.05 to 1.0. There are no data available for collectors larger than $300 \mu \mathrm{m}$ in radius, a size range that has appreciable concentrations in medium to heavy rain, or for particles with size ratios less than 0.05 , which can include particles from 0.5 to $10 \mu \mathrm{m}$ in radius. As well, collision efficiencies for collectors smaller than $30 \mu \mathrm{m}$ were later found to be underestimated (Vohl et al., 2007). These deficiencies appear to be the main causes of the lower values of $\Lambda_{\text {rain }}$ for particles in the diameter range from 1.0 to $10.0 \mu \mathrm{m}$ compared to the rest of the $\Lambda_{\text {rain }}$ formulas.

The above examination suggests that the two groups of $\Lambda_{\text {rain }}$ profiles that used the $E\left(d, D_{\mathrm{p}}\right)$ formulation of Park et al. (2005) and Ackerman et al. (1995) were not as realistic as the rest of the $\Lambda_{\text {rain }}$ profiles. We thus removed the $\Lambda_{\text {rain }}$ profiles based on the $E\left(d, D_{\mathrm{p}}\right)$ formulation of Park et al. (2005) from further consideration since there was no easy way to fix the problem. We noticed, however, that Vohl et al. (2007) had updated the Hall (1980) table with new experimental results that provided more realistic collision efficiencies for wider size ranges for both collector and collected particles. Thus, we chose to keep the $\Lambda_{\text {rain }}$ profiles based on the $E\left(d, D_{\mathrm{p}}\right)$ scheme of Ackerman et al. (1995) for further analysis, but these were modified profiles based on the updated collision efficiency table of Vohl et al. (2007) in place of the Hall (1980) table.

With this finalized selection of the available $E\left(d, D_{\mathrm{p}}\right)$ formulas (Table 1), there are $320 \Lambda_{\text {rain }}$ profiles based on different combinations of the product terms that are retained for further analysis (Fig. 1b). The use of the revised Ackerman et al. (1995) $E\left(d, D_{\mathrm{p}}\right)$ scheme dramatically changed the corresponding $80 \Lambda_{\text {rain }}$ profiles (the red lines in Fig. 1b), whose magnitudes increased by a factor of 2-3 for large particles $(d>10 \mu \mathrm{m})$ and over an order of magnitude for particles between $3.0 \mu \mathrm{m}$ and $10.0 \mu \mathrm{m}$ in diameter. The revised 
(a)

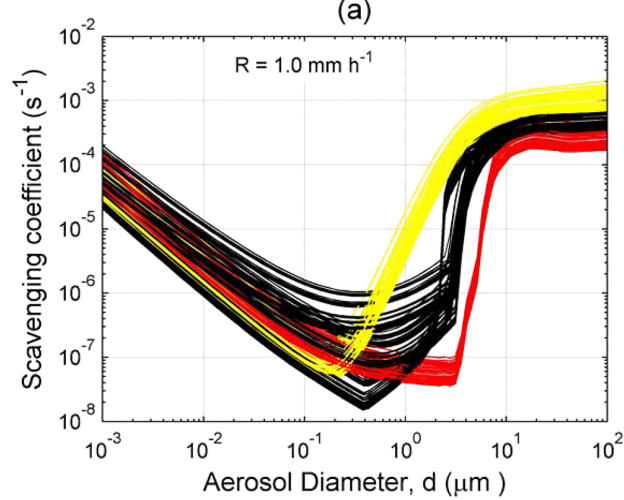

(c)

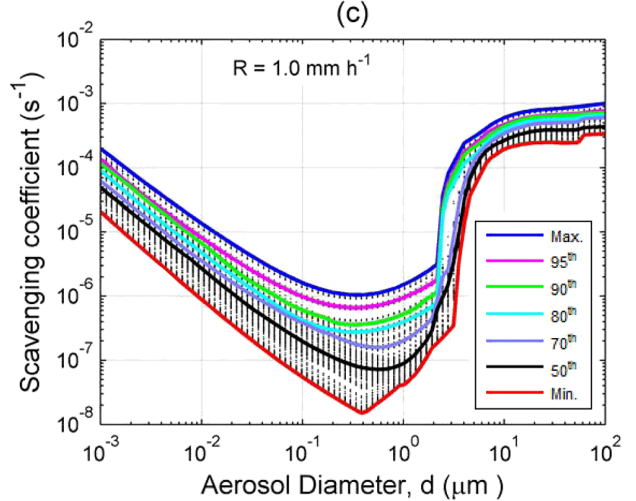

(b)

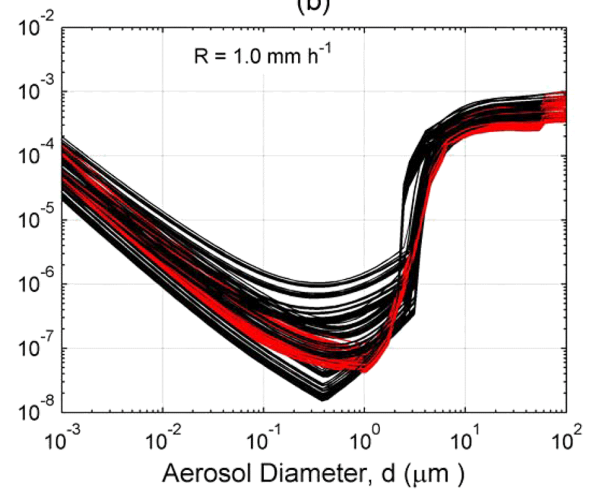

(d)

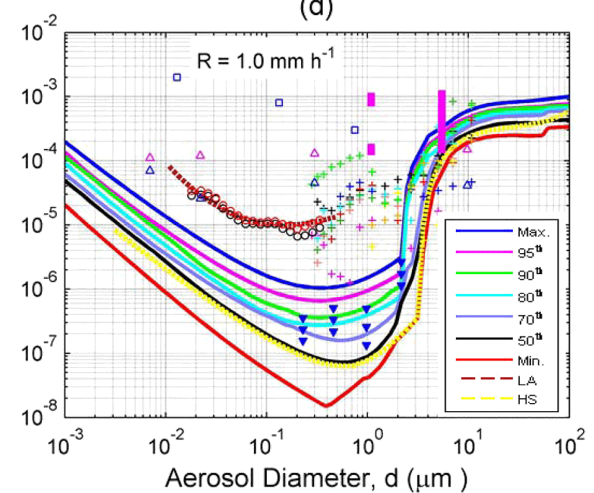

Fig. 1. Size-resolved scavenging coefficients for rain conditions: (a) $\Lambda_{\text {rain }}$ calculated using Eq. (2) from a total of 400 combinations of different $E\left(d, D_{\mathrm{p}}\right), N\left(D_{\mathrm{p}}\right)$, and $V_{D}$ formulas listed in Tables 1, 2, and 3, respectively. The yellow group uses the $E\left(d, D_{\mathrm{p}}\right)$ formula of Park et al. (2005) and the red group uses the $E\left(d, D_{\mathrm{p}}\right)$ formula of Ackerman et al. (1995); the black group includes all the other combinations; (b) same as in (a) but with the yellow group removed and the red group using the modified $E\left(d, D_{\mathrm{p}}\right)$ formula of Ackerman et al. (1995) (reduced to a total of 320 combinations); (c) minimum, maximum, and five percentile $\Lambda_{\text {rain }}$ profiles (colored lines) based on ensemble of profiles from (b), where dots are the data from (b); (d) lines are the same as (c) and symbols are experimental data reviewed in Wang et al. (2010). Also shown in (d) are one empirical $\Lambda_{\text {rain }}$ parameterization of Laakso et al. (2003) (denoted by LA; see Appendix A) and one semi-empirical $\Lambda_{\text {rain }}$ parameterization of Henzing et al. (2006) (denoted by HS; see Appendix B), which is an empirical fit to theoretically calculated $\Lambda_{\text {rain }}$ values.

$\Lambda_{\text {rain }}$ profiles were also comparable to the other $240 \Lambda_{\text {rain }}$ profiles that used different $E\left(d, D_{\mathrm{p}}\right)$ formulas (see the large group of black lines in Fig. 1b). Thus, it is recommended that the Hall (1980) table should be used with caution in the parameterization of $\Lambda_{\text {rain }}$ in CTMs.

Using the $320 \Lambda_{\text {rain }}$ profiles shown in Fig. 1b, we identified a number of percentile values of $\Lambda_{\text {rain }}$ for each aerosol particle diameter. These maximum, 95th-, 90th-, 80th-, 70th-, and 50th-percentile, and minimum $\Lambda_{\text {rain }}$ profiles are shown in Fig. 1c. Note that the dots in this panel correspond to the original $\Lambda_{\text {rain }}$ values shown in Fig. $1 \mathrm{~b}$ and the lines are the calculated percentile $\Lambda_{\text {rain }}$ profiles. Note also that the percentile profiles in Fig. 1c may not match exactly with any of the $\Lambda_{\text {rain }}$ profiles shown in Fig. 1b, but they represent the range and distribution of the ensemble of all theoretical $\Lambda_{\text {rain }}$ values across the range of different aerosol particle sizes.

In Fig. 1d the percentile $\Lambda_{\text {rain }}$ profiles are compared with the available $\Lambda_{\text {rain }}$ measurements and one empirical formula
(Laakso et al., 2003: see Appendix A) that were summarized in Wang et al. (2010). Note that the blue solid triangles in this panel come from the controlled outdoor experiment of Sparmacher et al. (1993) while the other symbols come from in situ field measurements made by different researchers. Note that even the maximum theoretical $\Lambda_{\text {rain }}$ values are smaller than the majority of field-experiment-derived values and those from the empirical formula of Laakso et al. (2003), and the differences can be larger than one order of magnitude for particles smaller than $3 \mu \mathrm{m}$. However, the 50th- to 90th-percentile theoretical $\Lambda_{\text {rain }}$ profiles seem to agree reasonably well with the $\Lambda_{\text {rain }}$ values estimated from the controlled outdoor experiment of Sparmacher et al. (1993). It is also worth noting that the $\Lambda_{\text {rain }}$ profile from the parameterization of Henzing et al. (2006), which was developed using a three-parameter fit to a set of pre-calculated $\Lambda_{\text {rain }}$ values generated from a theoretical $\Lambda_{\text {rain }}$ formulation (see Appendix B), 
Table 2. List of raindrop number size distribution $\left(N\left(D_{\mathrm{p}}\right)\right)$ formulas. The general forms of the (a) exponential, (b) gamma, and (c) log-normal distributions are commonly written as $N\left(D_{\mathrm{p}}\right)=N_{0 \mathrm{e}} \exp \left(-\beta_{\mathrm{e}} D_{\mathrm{p}}\right), N\left(D_{\mathrm{p}}\right)=N_{0 \mathrm{~g}} D_{\mathrm{p}}^{\gamma} \exp \left(-\beta_{\mathrm{g}} D_{\mathrm{p}}\right)$, and $N\left(D_{\mathrm{p}}\right)=$ $\frac{N_{\text {total }}}{\sqrt{2 \pi} D_{\mathrm{p}} \ln \left(\sigma_{D}\right)} \exp \left[-\frac{\left(\ln \left(D_{\mathrm{p}}\right)-\ln \left(D_{\text {mean }}\right)\right)^{2}}{2\left(\ln \left(\sigma_{D}\right)\right)^{2}}\right]$, respectively. See Table E1 in Appendix E for definitions of other symbols and units.

\begin{tabular}{|c|c|c|c|}
\hline $\begin{array}{l}\text { Raindrop number } \\
\text { size spectrum }\end{array}$ & Formula definition & Rain type & Source \\
\hline \multirow{5}{*}{$\begin{array}{l}\text { Exponential } \\
\text { distributions }\end{array}$} & $N_{0 \mathrm{e}}=0.08, \quad \beta_{\mathrm{e}}=41 R^{-0.21}$ & Widespread & Marshall and Palmer (1948) \\
\hline & $N_{0 \mathrm{e}}=0.30, \quad \beta_{\mathrm{e}}=57 R^{-0.21}$ & Drizzle & Joss et al. (1968) \\
\hline & $N_{0 \mathrm{e}}=0.014, \quad \beta_{\mathrm{e}}=30 R^{-0.21}$ & Thunderstorm & Joss et al. (1968) \\
\hline & $N_{0 \mathrm{e}}=0.07 R^{0.37}, \quad \beta_{\mathrm{e}}=38 R^{-0.14}$ & Thunderstorm & Sekhon and Srivastava (1971) \\
\hline & $\begin{array}{l}N_{0 \mathrm{e}}=0.071 M^{0.648}, \quad \beta_{\mathrm{e}}=\left(\frac{10^{-6} \rho_{\mathrm{w}} \pi N_{0 \mathrm{e}}}{M}\right)^{0.25} \\
M=0.0626 R^{0.913}\end{array}$ & Convective & Zhang et al. (2008) \\
\hline \multirow[t]{3}{*}{$\begin{array}{l}\text { Gamma } \\
\text { distributions }(b)\end{array}$} & $\begin{array}{l}N_{0 \mathrm{~g}}=168.53 R^{-0.384} \\
\gamma=2.93, \quad \beta_{\mathrm{g}}=53.8 R^{-0.186}\end{array}$ & Widespread & de Wolf (2001) \\
\hline & $\begin{array}{l}N_{0 \mathrm{~g}}=\frac{6.36 \times 10^{-4} M}{d_{0}^{4}}\left(\frac{1}{d_{0}}\right)^{2.5} \\
\gamma=2.50, \quad \beta_{\mathrm{g}}=5.57 / d_{0} \\
d_{0}=0.157 M^{0.168}, \quad M=0.062 R^{0.913}\end{array}$ & Hurricane & Willis (1984) \\
\hline & $\begin{array}{l}N_{0 \mathrm{~g}}=\frac{5.1285 \times 10^{-4} M}{d_{0}^{4}}\left(\frac{1}{d_{0}}\right)^{2.16} \\
\gamma=2.16, \quad \beta_{\mathrm{g}}=5.588 / d_{0} \\
d_{0}=0.1571 M^{0.1681}, \quad M=0.062 R^{0.913}\end{array}$ & Hurricane & Willis and Tattelman (1989) \\
\hline \multirow[t]{2}{*}{$\begin{array}{l}\text { Log-normal } \\
\text { distributions }(\mathrm{c})\end{array}$} & $\begin{array}{l}N_{\text {total }}=1.72 \times 10^{-4} R^{0.22}, \quad D_{\text {mean }}=0.072 R^{0.23} \\
\sigma_{D}=1.43-3.0 \times 10^{-4} R\end{array}$ & Widespread & Feingold and Levin (1986) \\
\hline & $\begin{array}{l}N_{\text {total }}=1.94 \times 10^{-4} R^{0.30}, \quad D_{\text {mean }}=0.063 R^{0.23} \\
\sigma_{D}=e^{\sqrt{0.191-1.1 \times 10^{-2} \cdot \ln (R)}}\end{array}$ & Widespread & Cerro et al. (1997) \\
\hline
\end{tabular}

falls into the lower range of the ensemble of available theoretical $\Lambda_{\text {rain }}$ values.

The large differences in $\Lambda_{\text {rain }}$ between the in situ fieldderived values and those from the controlled outdoor experiment and between the field experiments and the theoretical formulations are caused by many different factors. Some of the differences might reflect the uncontrolled real-world situation while others are due to experimental errors and to errors in the theoretical formulations (Khain and Pinsky, 1997; Maria and Russell, 2005; Andronache et al., 2006; Wang et al., 2011; Quérel, 2012; Quérel et al., 2013). Choosing the upper range of theoretical $\Lambda_{\text {rain }}$ values for applications in CTMs appears to be a reasonable choice because these values are only slightly higher than the corresponding values from the controlled outdoor experiment but are still lower than values from the majority of field experiments. Thus, the 90th percentile of the range of the ensemble of theoretical $\Lambda_{\text {rain }}$ profiles was chosen for further analysis and parameterization development.

Moving to step 3 in Sect. 2, we repeated the calculation of $\Lambda_{\text {rain }}$ with Eq. (2) for all of the 320 combinations of product-term formulas for each of 37 different precipitation intensities $R$, which covered the range of values from 0.01 to $100 \mathrm{~mm} \mathrm{~h}^{-1}$ and were uniformly distributed logarithmically (same as the tick values shown in $x$ axis of Fig. 2b). Furthermore, 90th-percentile $\Lambda_{\text {rain }}$ values were then calculated from the ensemble of theoretical $\Lambda_{\text {rain }}$ profiles for each aerosol particle diameter bin $d$ and every precipitation intensity $R$. These 90th-percentile $\Lambda_{\text {rain }}$ data are plotted against precipitation intensity in Fig. $2 \mathrm{a}$ as a set of 100 lines, with each line representing one aerosol particle diameter and in the form of $\Lambda_{\text {rain }}$ vs. $R$.

Regression analysis suggests that for each aerosol particle diameter (i.e., each individual line in Fig. 2a), there exists a strong linear relationship between $\log _{10}\left(\Lambda_{\text {rain }}\right)$ and $\log _{10}(R)$, or in other words a power-law relationship between $\Lambda_{\text {rain }}$ and $R$, which can be expressed as

$\log _{10}(\Lambda(d, R))=\log _{10}(A(d))+B(d)\left(\log _{10} R\right)$,

$\Lambda(d, R)=A(d) R^{B(d)}$. 
Table 3. List of empirical and theoretical raindrop terminal velocity $\left(V_{D}\right)$ formulas.

\begin{tabular}{|c|c|c|}
\hline Type & Formula & Source \\
\hline \multirow{6}{*}{$\begin{array}{l}\text { Empirical } \\
\text { formulas }\end{array}$} & $V_{D}=1300 D_{\mathrm{p}}^{0.5}$ & Kessler (1969) \\
\hline & $V_{D}=1767 D_{\mathrm{p}}^{0.67}$ & Atlas and Ulbrich (1977) \\
\hline & $V_{D}=4854 D_{\mathrm{p}} \exp \left(-1.95 D_{\mathrm{p}}\right)$ & Willis (1984) \\
\hline & $V_{D}=958\left[1-\exp \left(-\left(\frac{D_{\mathrm{p}}}{0.171}\right)^{1.147}\right)\right]$ & Best (1950) \\
\hline & $V_{D}=-10.21+4932 D_{\mathrm{p}}-9551 D_{\mathrm{p}}^{2}+7934 D_{\mathrm{p}}^{3}-2362 D_{\mathrm{p}}^{4}$ & Brandes et al. (2002) \\
\hline & $V_{D}= \begin{cases}0 & D_{\mathrm{p}} \leq 0.003 \\
4323\left(D_{\mathrm{p}}-0.003\right) & 0.003 \leq D_{\mathrm{p}} \leq 0.06 \\
965-1030 \exp \left(-6 D_{\mathrm{p}}\right) & D_{\mathrm{p}}>0.06\end{cases}$ & Henzing et al. (2006) \\
\hline \multirow{2}{*}{$\begin{array}{l}\text { Theoretical } \\
\text { formulas }\end{array}$} & Beard's scheme & Beard (1976) \\
\hline & Feng's Scheme & Feng (2007) \\
\hline
\end{tabular}

(a)

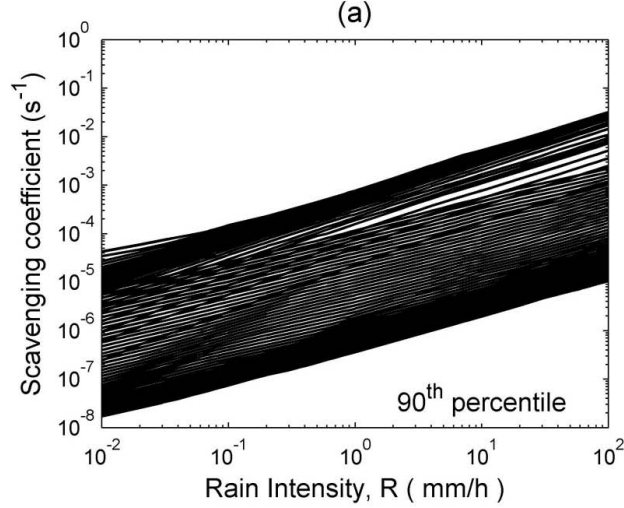

(c)

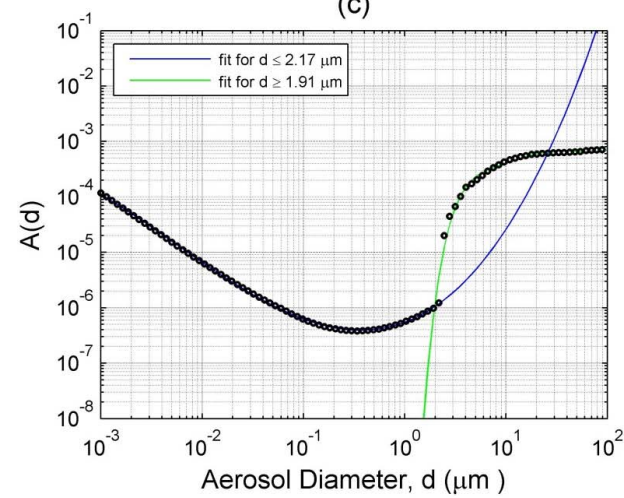

(b)

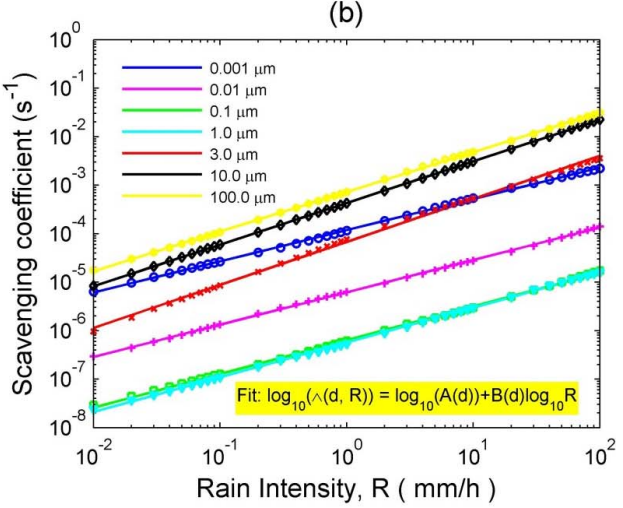

(d)

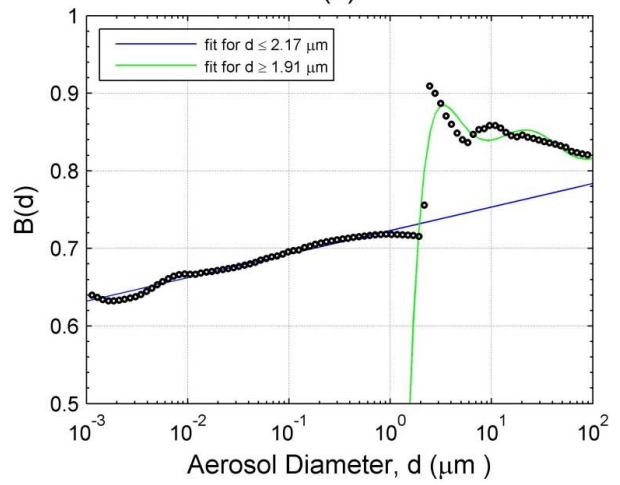

Fig. 2. (a) 90th-percentile $\Lambda_{\text {rain }}$ profiles as a function of precipitation intensity $R$ derived from an ensemble of $320 \Lambda_{\text {rain }}$ realizations for 100 particle diameters (a total of 100 lines); (b) linear regression best-fit lines for the 90th-percentile $\Lambda_{\text {rain }}$ data (symbols) from (a) for seven aerosol particle diameters; (c) values (symbols) of $y$ intercept $A(d)$ from the log-linear regressions for 100 particle diameters and their polynomial best-fit curves (lines); and (d) same as in (c) but for the slope $B(d)$ of the log-linear regressions.

Linear regression analysis based on Eq. (4) was performed for all 100 lines and the squares of the resulting correlation coefficients were very high, ranging from 0.9963 to 1.0. Figure $2 b$ shows seven of these regression lines for seven selected aerosol particle diameters with the original data (the 90th-percentile $\Lambda_{\text {rain }}$ values for $37 R$ values) shown as symbols. $B(d)$ values were obtained for all 100 aerosol sizes directly from the regression analysis. It is apparent from this 
(a)

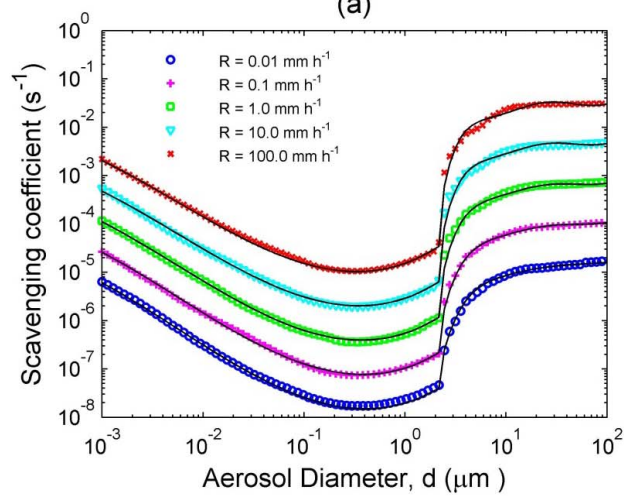

(b)

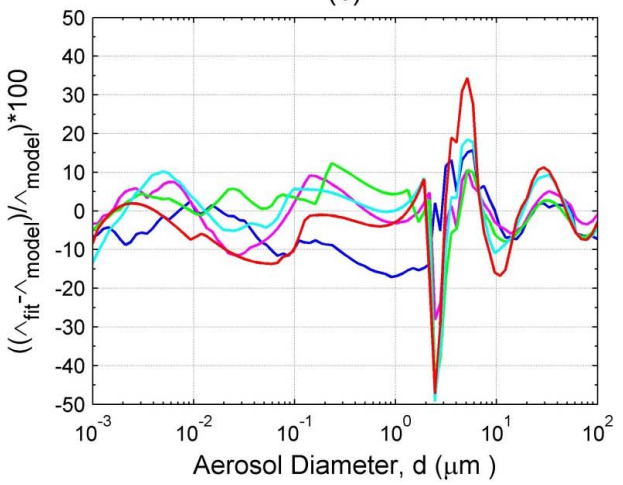

Fig. 3. Parameterized size-resolved $\Lambda_{\text {rain }}$ profiles using Eqs. (5), (6), and (7) (solid lines) and the original 90th-percentile $\Lambda_{\text {rain }}$ data (symbols) (a) and their percentage differences (b) for five different precipitation intensities.

panel that both the slope of the regression lines $(B(d))$ and its $y$ intercept $\left(\log _{10} A(d)\right)$ may vary with aerosol particle diameter. Note, however, that the $y$ intercept does not cross the $y$ axis shown in Fig. $2 \mathrm{~b}$ because the actual $R$ value instead of $\log _{10}(R)$ is used for the $x$ axis. But according to Eq. (4), $A(d)$ equals $\Lambda_{\text {rain }}(d, 1)$ (i.e., when $R=1.0 \mathrm{~mm} \mathrm{~h}^{-1}$ ), so $A(d)$ values are also readily available. The resulting $A(d)$ and $B(d)$ values are plotted in Fig. 2c and d, respectively, for each of 100 aerosol particle diameters.

Since $A(d)$ and $B(d)$ correspond at this stage to sets of discrete data, a least-square polynomial curve-fitting technique was used to fit these power-law coefficient data and parameterize $A(d)$ and $B(d)$ as continuous functions of aerosol particle diameter. Due to the abrupt change of the values of both $A(d)$ and $B(d)$ at particle diameters between 1 and $2 \mu \mathrm{m}$, the particle diameter range of each of the two data sets was split into two contiguous segments for separate but more accurate fitting. After many tests, the separation point of the two segments was determined to be $1.97 \mu \mathrm{m}$ for $A(d)$ (see Fig. 2c) and $1.94 \mu \mathrm{m}$ for $B(d)$ (see Fig. $2 \mathrm{~d}$ ). We thus chose $2.0 \mu \mathrm{m}$ to be the separation point for both the $A(d)$ and $B(d)$ curve fits. After some experimentation, the following polynomial functions (up to sixth order) were selected for fitting the four segments:

$\log _{10}(A(d))=\left\{\begin{array}{cc}a_{0}+a_{1}\left(\log _{10} d\right)+a_{2}\left(\log _{10} d\right)^{2} & \\ +a_{3}\left(\log _{10} d\right)^{3} & d \leq 2.0 \mu \mathrm{m} \\ b_{0}+b_{1}\left(\log _{10} d\right)+b_{2}\left(\log _{10} d\right)^{2} & \\ +b_{3}\left(\log _{10} d\right)^{3}+b_{4}\left(\log _{10} d\right)^{4} & \\ +b_{5}\left(\log _{10} d\right)^{5}+b_{6}\left(\log _{10} d\right)^{6} & d>2.0 \mu \mathrm{m}\end{array}\right.$

$B(d)= \begin{cases}c_{0}+c_{1}\left(\log _{10} d\right) & d \leq 2.0 \mu \mathrm{m} \\ e_{0}+e_{1}\left(\log _{10} d\right)+e_{2}\left(\log _{10} d\right)^{2} & \\ +e_{3}\left(\log _{10} d\right)^{3}+e_{4}\left(\log _{10} d\right)^{4} & \\ & +e_{5}\left(\log _{10} d\right)^{5}+e_{6}\left(\log _{10} d\right)^{6} \quad d>2.0 \mu \mathrm{m} .\end{cases}$

Note that the unit of $d$ is $\mu \mathrm{m}$, and the above equations should be applied to wet aerosol diameter. The empirical best-fit coefficients that were obtained for the above equations are listed in Table 8.
A comparison of $\Lambda_{\text {rain }}$ values predicted by the new parameterization described by Eqs. (5), (6), and (7) with the data used for developing the parameterization (the 90th-percentile $\Lambda_{\text {rain }}(d, R)$ values) is shown in Fig. 3a for five different precipitation intensities. Very good agreement is evident for the full range of aerosol particle size and full range of precipitation intensity. To further examine the comparison shown in Fig. 3a, the relative error between $\Lambda_{\text {rain }}$ values from the new parameterization and the original 90th-percentile values was also calculated (Fig. 3b). The relative error was within $10 \%$ for most of the aerosol particle sizes, except for the 2 $6 \mu \mathrm{m}$ diameter range for which the error could be larger than $30 \%$. The largest relative errors corresponded to the aerosol particle diameters where $\Lambda_{\text {rain }}$ increased abruptly with particle diameter. It should also be noted that various particle-size separation points were tested for the separate fits of Eqs. (6) and (7) (e.g., from 1.9 to $2.2 \mu \mathrm{m}$ ), and a separation point of $2.0 \mu \mathrm{m}$ does lead to the minimum relative errors for most aerosol sizes.

To gain an idea of how $A(d)$ and $B(d)$ in Eqs. (6) and (7) would differ if $\Lambda_{\text {rain }}(d, R)$ values other than 90th-percentile ones had been used, a separate empirical fitting was performed using 50th-percentile values. It was found that $B(d)$ values did not change by very much, whereas $A(d)$ values differed by one order of magnitude. As noted above, $B(d)$ represents the rate of change of $\Lambda_{\text {rain }}(d, R)$ for changes of $R$ while $A(d)$ represents the $\Lambda_{\text {rain }}(d, R)$ value when $R=$ $1.0 \mathrm{~mm} \mathrm{~h}^{-1}$. This means that $\Lambda_{\text {rain }}(d, R)$ for the 90 th and 50th percentiles vary similarly with changes in $R$, but the magnitude of the 90th-percentile $\Lambda_{\text {rain }}(d, R)$ is much larger than the 50th-percentile $\Lambda_{\text {rain }}(d, R)$.

Overall, this new simple semi-empirical parameterization provides a good fit of the original $\Lambda_{\text {rain }}$ data for all aerosol particle sizes and precipitation intensities. As well, uncertainties associated with the use of this new scheme in CTMs to parameterize $\Lambda_{\text {rain }}$ should not be larger than those shown by Wang et al. (2010) to be associated with the existing theoretical formulas. The $\Lambda(d)$ profile generated from the new 
Table 4. List of semi-empirical formulas for snow particle-aerosol particle collection efficiency $E$.

\begin{tabular}{|c|c|}
\hline Source & Formula \\
\hline Slinn $(1984)^{\mathrm{a}}$ & $E(d, \lambda)=\left(\frac{1}{S c}\right)^{\alpha_{\lambda}}+\left[1-\exp \left(-\left(1+\operatorname{Re}_{\lambda}^{1 / 2}\right)\right) \frac{(d / 2)^{2}}{\lambda^{2}}\right]+\left(\frac{S t-S t^{*}}{S t-S t^{*}+2 / 3}\right)^{3 / 2}$ \\
\hline Murakami et al. $(1985)^{\mathrm{b}}$ & $E\left(d, D_{\mathrm{m}}\right)=\frac{48 D_{\mathrm{diff}}}{\pi D_{\mathrm{m}} V_{D}}\left(0.65+0.44 S c^{1 / 3} R e^{1 / 2}\right)+28.5 I^{1.186}+\left(\frac{S_{1}-S_{2}}{S_{2} \exp \left(S_{1} t^{\prime}\right)-S_{1} \exp \left(S_{2} t^{\prime}\right)}\right)^{2}$ \\
\hline $\operatorname{Dick}(1990)^{\mathrm{c}}$ & $E\left(d, D_{\mathrm{m}}\right)=\frac{2 m V_{D}}{3 \pi d \mu_{\mathrm{a}} D_{\mathrm{m}}}+\frac{4}{P e}\left(1+0.4 R e^{1 / 6} P e^{1 / 3}\right)$ \\
\hline \multicolumn{2}{|c|}{$\begin{array}{l}\text { a } \lambda \text { is the characteristic capture length and } \alpha_{\lambda} \text { is an empirical constant. Both } \lambda \text { and } \alpha_{\lambda} \text { depend on the shape of snow particles (e.g., sleet/graupel, rimed } \\
\text { crystals, powder snow, dendrite, tissue paper, and camera film). } R e_{\lambda} \text { is the Reynolds number corresponding to the specific } \lambda \text {, } S c \text { is the Schmidt number: } \\
S c=\mu_{\mathrm{a}} / \rho_{\mathrm{a}} D_{\text {diff }}, S t \text { is the Stokes number, and } S t^{*} \text { is the critical Stokes number: } S t^{*}=\frac{1.2+(1 / 12) \ln \left(1+R e_{\lambda}\right)}{1+\ln (1+R e \lambda)} \text {. }\end{array}$} \\
\hline $\begin{array}{l}\mathrm{b} \text { The formula is for snow aggregat } \\
\text { ratio } d / D_{\mathrm{c}} \text { with } D_{\mathrm{c}} \text { the characteris } \\
\text { Wong }(1952) \text {, involving parameter }\end{array}$ & $\begin{array}{l}\text { s. The Reynolds number of a snow particle is defined as } R e=D_{\mathrm{m}} V_{D} \rho_{\mathrm{a}} / \mu_{\mathrm{a}}, S c \text { is the Schmidt number, and } I \text { is the siz } \\
\mathrm{c} \text { length of the snow particle. The third term is the theoretical solution of a simplified flow model by Ranz and } \\
S_{1}, S_{2} \text { and } t^{\prime} \text {, and it can be simplified to } \exp \left(\frac{-0.11}{S t^{1 / 2}-0.25}\right) \text { if } S t \geq 1 / 16 \text {, or to } 0 \text { if } S t<1 / 16 \text { (Feng, 2009). }\end{array}$ \\
\hline
\end{tabular}

Table 5. List of exponential snow particle number size distribution $\left(N\left(D_{\mathrm{p}}\right)\right)$ formulas. Note that actual snow particle size $D_{\mathrm{m}}(\mathrm{cm})$ was used in Scott (1982) (see Appendix A in Zhang et al., 2013), whereas $D_{\mathrm{p}}$ was used in other formulas.

\begin{tabular}{lll} 
& $N\left(D_{\mathrm{p}}\right)=N_{0 \mathrm{e}} \exp \left(-\beta_{\mathrm{e}} D_{\mathrm{p}}\right)$ \\
\hline Source & $N_{0 \mathrm{e}}\left[\mathrm{cm}^{-4}\right]$ & $\beta_{\mathrm{e}}\left[\mathrm{cm}^{-1}\right]$ \\
\hline Marshall and Palmer (1948) & 0.08 & $\beta_{\mathrm{e}}=41 R^{-0.21}$ \\
\hline Scott (1982) & 0.5 & $\begin{array}{l}M=0.37 R^{0.94} \\
\beta_{\mathrm{e}}=20.7 M^{-0.33}=28.8 R^{-0.31}\end{array}$ \\
\hline Gunn and Marshall (1958) & $N_{0 \mathrm{e}}=0.038 R^{-0.87}$ & $\beta_{\mathrm{e}}=25.5 R^{-0.48}$ \\
\hline Sekhon and Srivastava (1970) & $N_{0 \mathrm{e}}=0.025 R^{-0.94}$ & $\beta_{\mathrm{e}}=22.9 R^{-0.45}$ \\
\hline
\end{tabular}

parameterization does not exactly match any of the existing theoretical profiles considered, but for all aerosol particle diameters its values will lie within the upper range of an ensemble of theoretical $\Lambda(d)$ values obtained from all possible combinations of existing product-term formulas. The new parameterization is designed for use in CTMs to describe below-cloud scavenging of size-resolved aerosol particles. We believe it to be a reasonable first-order approximation for any precipitation conditions, either stratiform or convective, considering that precipitation intensity and precipitation type (i.e., rain or snow) are likely to be the only precipitation information available in many CTMs (e.g., information on different rain types or droplet size distributions may not be available).

\section{$3.2 \Lambda_{\text {snow }}$}

The development of the new semi-empirical parameterization for $\Lambda_{\text {snow }}$ follows the same approach described above for $\Lambda_{\text {rain }}$. The first step was to calculate an ensemble of theoretical $\Lambda_{\text {snow }}$ profiles across the aerosol particle size spectrum using Eq. (2) for a precipitation intensity of $1.0 \mathrm{~mm} \mathrm{~h}^{-1}$ for all possible combinations of the product terms listed in Tables 4-7. There are three $E\left(d, D_{\mathrm{p}}\right)$, four $N\left(D_{\mathrm{p}}\right)$, eight $V_{D}$, and four $A$ formulas available in the literature related to snow particles, but some of the $V_{D}$ formulas were only applicable to specific snow types. Thus, a total of 168 combinations of these product-term formulas were used to calculate $\Lambda_{\text {snow }}$ profiles (see Fig. 4a). Note that these formulas cover four habit types of snow crystals - spherical ice crystals, dendritic snow plates, columnar ice crystals, and graupel particles (see Table 7), all of which occur frequently in nature (e.g., Hobbs et al., 1972).

As discussed in Zhang et al. (2013), the range of the ensemble of available theoretical $\Lambda_{\text {snow }}$ formulations is much larger than that for $\Lambda_{\text {rain }}$ (compare Fig. 4a with Fig. 1b). It is likely that part of this larger range is due to real variability (e.g., different snow particle shapes and related properties affecting $\Lambda_{\text {snow }}$ ) while the other part is due to parameterization errors (e.g., improper formulation of related parameters). Examining the ensemble of $\Lambda_{\text {snow }}$ profiles plotted in Fig. 4a (i.e., step 2), we did not find any obviously unrealistic profiles. The two clusters with distinct minima were caused by different formulas applying to different snow particle shapes and should not be considered as unrealistic (cf., Figs. 1, 2, and 8 of Zhang et al., 2013). Considering that information about snow particle shapes is not commonly available in CTMs, we chose to group all of the existing 
(a)

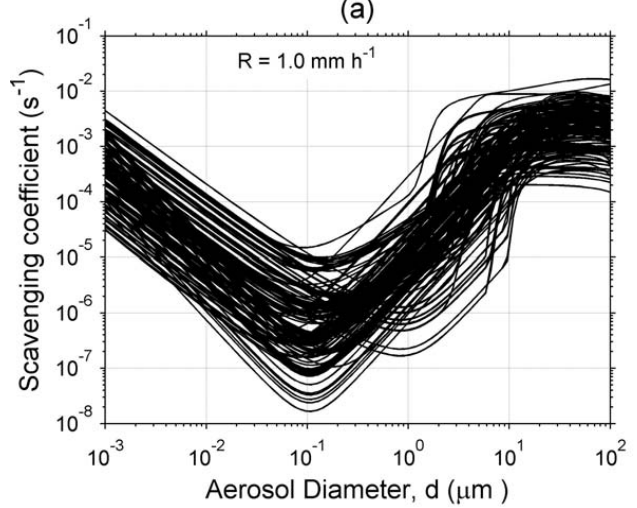

(b)

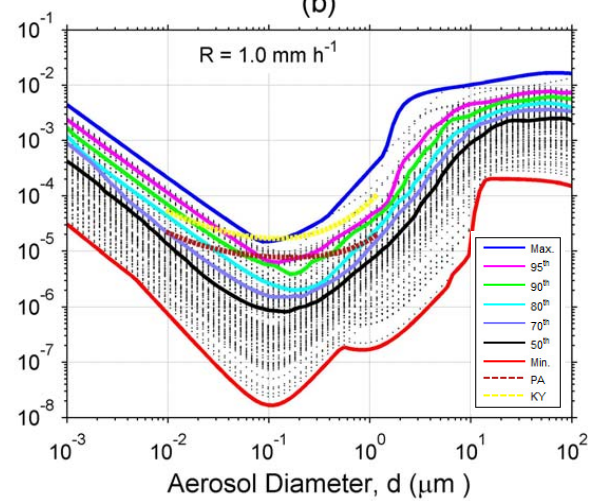

Fig. 4. Size-resolved scavenging coefficient under snow conditions: (a) $\Lambda_{\text {snow }}$ calculated using Eq. (2) from a total of 168 combinations of $E\left(d, D_{\mathrm{p}}\right), N\left(D_{\mathrm{p}}\right), V_{D}$ and $A$ listed in Tables 4, 5, 6, and 7, respectively; and (b) minimum, maximum, and five percentile $\Lambda_{\text {snow }}$ profiles (colored lines) based on ensemble of profiles from (a), where dots are the data from (a). Also shown in (b) are two empirical $\Lambda_{\text {snow formulas }}$ of Paramonov et al. (2011) and Kyrö et al. (2009) (Appendices C and D, respectively).

Table 6. List of empirical and theoretical snow particle terminal velocity $\left(V_{D}\right)$ formulas. $X$ is the best number: $X=\frac{2 m g \rho_{\mathrm{a}} D_{\mathrm{m}}^{2}}{A \mu_{\mathrm{a}}^{2}}, \alpha, \beta, \delta$, and $\sigma$ are empirical constants (see Table 7), and $a_{1}$ and $b_{1}$ are described as functions of $X$ (see Mitchell and Heymsfield, 2005).

\begin{tabular}{lll}
\hline Source & $V_{D}$ formula & Particle shape \\
\hline Langleben (1954) & $V_{D}=207.0 D_{\mathrm{p}}^{0.310}$ & plane dendrite \\
Jiusto and Bosworth (1971) & $V_{D}=104.9 D_{\mathrm{m}}^{0.206}$ & plane dendrite \\
Locatelli and Hobbs (1974) & $V_{D}=64.80 D_{\mathrm{m}}^{0.257}$ & plane dendrite \\
Molthan et al. (2010) & $V_{D}=110.1 D_{\mathrm{m}}^{0.145}$ & plane dendrite \\
Jiusto and Bosworth (1971) & $V_{D}=153.0 D_{\mathrm{m}}^{0.206}$ & column \\
Matson and Huggins (1980) & $V_{D}=1145 D_{\mathrm{p}}^{0.500}$ & graupel \\
Mitchell (1996) & $V_{D}=\frac{\operatorname{Re} \mu_{\mathrm{a}}}{D_{\mathrm{m}} \rho_{\mathrm{a}}}$ & any shape \\
$0.06049 X^{0.831}, 10.0<X \leq 585$ & \\
$0.2072 X^{0.638}, 585<X \leq 1.56 \times 10^{5}$ & \\
$1.0865 X^{0.499}, 1.56 \times 10^{5}<X \leq 10^{8}$ & \\
\hline Mitchell and Heymsfield (2005) & $V_{D}=a_{v} D_{\mathrm{m}}^{b_{v}}, R e=a_{1} X^{b_{1}}, m=\alpha D_{\mathrm{m}}^{\beta}, A=\delta D_{\mathrm{m}}^{\sigma}$ \\
& $R e$ & any shape
\end{tabular}

formulas together without explicit consideration of snow particle shape. Thus, all of the values in Fig. 4a were used for further analysis. Similar to Fig. 1c, the range and percentile values of $\Lambda_{\text {snow }}$ were also generated as shown in Fig. 4b. Also plotted are two field-derived empirical formulas for $\Lambda_{\text {snow }}$, one from Paramonov et al. (2011) (Appendix C) and one from Kyrö et al. (2009) (Appendix D), but it should be noted that both formulas are more applicable to weaker snowfall intensities (e.g., $0.1-0.2 \mathrm{~mm} \mathrm{~h}^{-1}$ ) than the intensity assumed in Fig. $4 \mathrm{~b}\left(1 \mathrm{~mm} \mathrm{~h}^{-1}\right)$ and are only valid for aerosol particle sizes in $0.01-1.0 \mu \mathrm{m}$ diameter range. Figure $4 \mathrm{~b}$ shows that the upper range of the theoretical $\Lambda_{\text {snow }}$ profiles calculated assuming a snowfall intensity of $1 \mathrm{~mm} \mathrm{~h}^{-1}$ are of the same order of magnitude as the limited field data, which were observed under mostly weaker snowfall intensities. The theoretical $\Lambda_{\text {snow }}$ profiles would be smaller than the experimental data if the same snowfall intensity as observed in the field were to be used for the calculation of $\Lambda_{\text {snow }}$ using Eq. (2). To be consistent with the choice made for $\Lambda_{\text {rain }}$, the 90th percentile of the ensemble of all theoretical $\Lambda_{\text {snow }}$ formulations at each aerosol particle diameter was also used to develop the new parameterization for $\Lambda_{\text {snow }}$. However, the evidence supporting this choice is somewhat weaker for $\Lambda_{\text {snow }}$ than for $\Lambda_{\text {rain }}$ due to the very limited field data for snow scavenging cases.

Theoretical size-resolved $\Lambda_{\text {snow }}$ values were calculated in step 3 using the 168 combinations of product-term formulas for each of 37 precipitation intensities uniformly distributed logarithmically from $0.001 \mathrm{~mm} \mathrm{~h}^{-1}$ to $10 \mathrm{~mm} \mathrm{~h}^{-1}$ in liquid water equivalent. Given that $10 \mathrm{~mm}$ of snow is approximately 
(a)

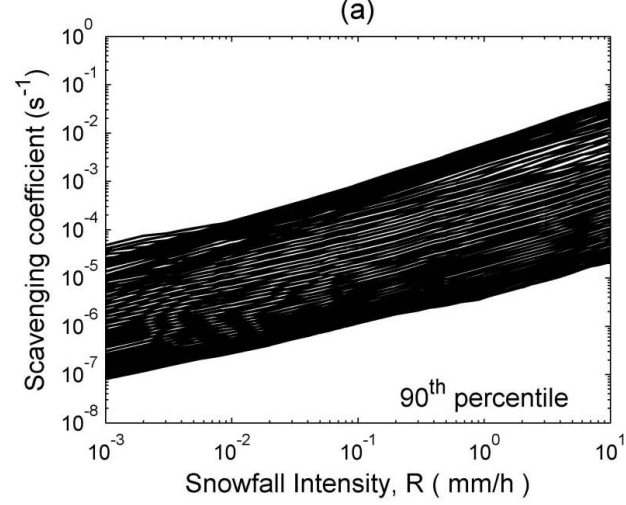

(c)

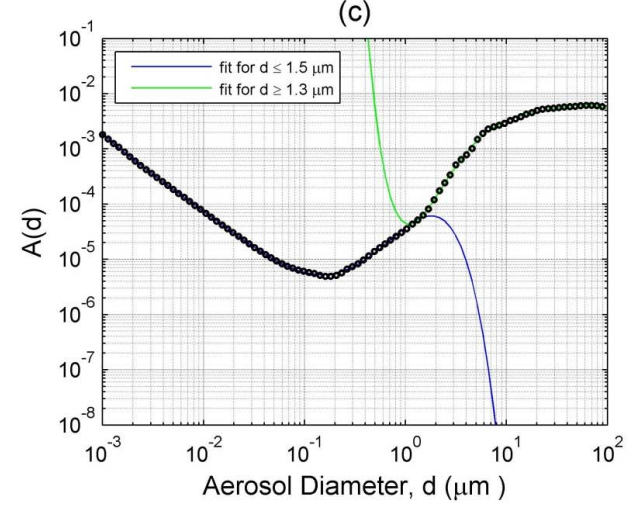

(b)

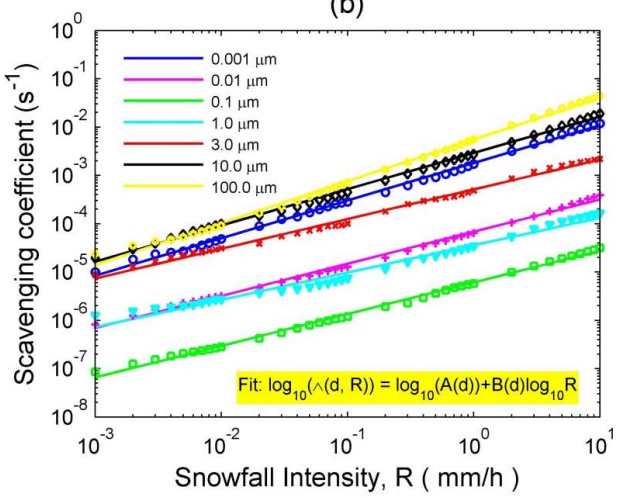

(d)

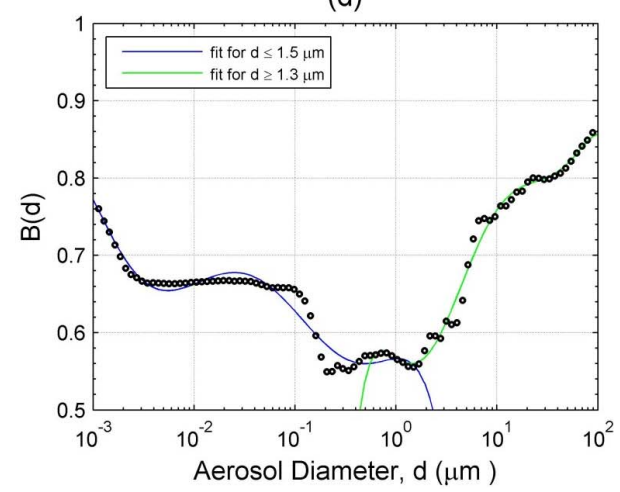

Fig. 5. Same as in Fig. 2 except for $\Lambda_{\text {snow }}$.

Table 7. Snow particle shapes considered in this study and their mass $(m)$ and cross-sectional area $(A)$ formulas.

\begin{tabular}{lll}
\hline $\begin{array}{l}\text { Snow particle } \\
\text { shape }\end{array}$ & $\begin{array}{l}\text { Mass } \\
m=\alpha D_{\mathrm{m}}{ }^{\beta}[\mathrm{g}]\end{array}$ & $\begin{array}{l}\text { Cross-sectional area } \\
A=\delta D_{\mathrm{m}}^{\sigma}\left[\mathrm{cm}^{2}\right]\end{array}$ \\
\hline Spheres & $m=0.0524 D_{\mathrm{m}}^{3.00, \mathrm{a}}$ & $A=0.7854 D_{\mathrm{m}}^{2.00, \mathrm{a}}$ \\
\hline Dendrites & $m=0.0022 D_{\mathrm{m}}^{2.19, \mathrm{~b}}$ & $A=0.2285 D_{\mathrm{m}}^{1.88, \mathrm{c}}$ \\
\hline Columns & $m=0.0450 D_{\mathrm{m}}^{3.00, \mathrm{~b}}$ & $A=0.0512 D_{\mathrm{m}}^{1.41, \mathrm{~d}}$ \\
\hline Graupel & $m=0.0490 D_{\mathrm{m}}^{2.80, \mathrm{e}}$ & $A=0.5000 D_{\mathrm{m}}^{2.00, \mathrm{e}}$ \\
\hline
\end{tabular}

${ }^{\text {a } O b t a i n e d ~ f r o m ~} m=\rho_{\mathrm{s}}(\pi / 6) D_{\mathrm{m}}^{3}$ and $A=(\pi / 4) D_{\mathrm{m}}^{2}$, with $\rho_{\mathrm{s}}=0.1 \mathrm{~g} \mathrm{~cm}^{-3}$.

b From Woods et al. (2008).

c From Mitchell (1996) for "aggregates of side planes".

d From Mitchell (1996) for "rimed long columns".

e From Mitchell (1996) for "lump graupel".

equivalent to $1 \mathrm{~mm}$ of rain, a different range of precipitation intensities was used to generate the $\Lambda_{\text {snow }}$ ensemble data set than that used in the $\Lambda_{\text {rain }}$ case. 90th-percentile $\Lambda_{\text {snow }}$ values for each aerosol particle diameter were then extracted for each precipitation intensity and are plotted in Fig. 5a, where again each line corresponds to a fixed aerosol particle diameter. The relationship between $\log _{10}\left(\Lambda_{\text {snow }}\right)$ and $\log _{10}(R)$ can also be described by Eq. (4). Linear regressions were again calculated, and the squares of the correlation coefficients of the 100 regressions were again very high, ranging from 0.9736 to 0.9997 . Seven of the 100 regression lines together with the data points being fit are plotted in Fig. $5 \mathrm{~b}$ as examples.

The same approach described in Sect. 3.1 was also used here to generate $\log _{10}(A(d))$ and $B(d)$ values (Fig. $5 \mathrm{c}$ and d) and to conduct least-squares polynomial curve-fitting to parameterize $\log _{10}(A(d))$ and $B(d)$ for all $d$ values. Again, the data sets were split into two contiguous segments for separate fitting. Multiple intersections between the two fitting functions were found for both the $\log _{10}(A(d))$ and $B(d)$ cases. This time a final separation point was chosen at a particle diameter of $1.44 \mu \mathrm{m}$ because this value produced the minimum relative errors between the parameterized and the original theoretical $\Lambda_{\text {snow }}$ values. The polynomial fitting formulas for the snow case are shown below and their corresponding empirical best-fit coefficients are listed in Table 8 .

$$
\log _{10}(A(d))=\left\{\begin{array}{c}
a_{0}+a_{1}\left(\log _{10} d\right)+a_{2}\left(\log _{10} d\right)^{2} \\
+a_{3}\left(\log _{10} d\right)^{3}+a_{4}\left(\log _{10} d\right)^{4} \\
+a_{5}\left(\log _{10} d\right)^{5}+a_{6}\left(\log _{10} d\right)^{6} \\
b_{0}+b_{1}\left(\log _{10} d\right)+b_{2}\left(\log _{10} d\right)^{2} \\
+b_{3}\left(\log _{10} d\right)^{3}+b_{4}\left(\log _{10} d\right)^{4} \\
+b_{5}\left(\log _{10} d\right)^{5}+b_{6}\left(\log _{10} d\right)^{6} \quad d>1.44 \mu \mathrm{m} \\
\quad d 4 \mu \mathrm{m}
\end{array}\right.
$$


Table 8. Empirical constants in the formulations of $\log _{10}(A(d))$ and $B(d)$ for $\Lambda_{\text {rain }}$ and $\Lambda_{\text {snow }}$ parameterizations.

\begin{tabular}{|c|c|c|c|c|c|c|c|}
\hline \multicolumn{8}{|c|}{ Constants in $\Lambda_{\text {rain }}$ parameterization } \\
\hline \multirow[t]{2}{*}{$\log _{10}(A(d))$} & $a_{0}=-6.2609 \times 10^{0}$ & $a_{1}=6.8200 \times 10^{-1}$ & $a_{2}=8.6760 \times 10^{-1}$ & $a_{3}=1.2820 \times 10^{-1}$ & & & \\
\hline & $b_{0}=-1.4707 \times 10^{1}$ & $b_{1}=5.1043 \times 10^{1}$ & $b_{2}=-9.7306 \times 10^{1}$ & $b_{3}=9.7946 \times 10^{1}$ & $b_{4}=-5.3923 \times 10^{1}$ & $b_{5}=1.5311 \times 10^{1}$ & $b_{6}=-1.7510 \times 10^{0}$ \\
\hline \multirow[t]{2}{*}{$B(d)$} & $c_{0}=7.2300 \times 10^{-1}$ & $c_{1}=3.0300 \times 10^{-2}$ & & & & & \\
\hline & $e_{0}=-6.4920 \times 10^{-1}$ & $e_{1}=9.3483 \times 10^{0}$ & $e_{2}=-2.1929 \times 10^{1}$ & $e_{3}=2.5317 \times 10^{1}$ & $e_{4}=-1.5395 \times 10^{1}$ & $e_{5}=4.7242 \times 10^{0}$ & $e_{6}=-5.7660 \times 10^{-1}$ \\
\hline \multicolumn{8}{|c|}{ Constants in $\Lambda_{\text {snow }}$ parameterization } \\
\hline \multirow[t]{2}{*}{$\log _{10}(A(d))$} & $a_{0}=-4.4260 \times 10^{0}$ & $a_{1}=1.3940 \times 10^{0}$ & $a_{2}=-1.2020 \times 10^{0}$ & $a_{3}=-3.2942 \times 10^{0}$ & $a_{4}=-1.9521 \times 10^{0}$ & $a_{5}=-4.9040 \times 10^{-1}$ & $a_{6}=-4.5700 \times 10^{-2}$ \\
\hline & $b_{0}=-4.3531 \times 10^{0}$ & $b_{1}=-7.8280 \times 10^{-1}$ & $b_{2}=1.2768 \times 10^{1}$ & $b_{3}=-1.9864 \times 10^{1}$ & $b_{4}=1.3618 \times 10^{1}$ & $b_{5}=-4.4350 \times 10^{0}$ & $b_{6}=5.5510 \times 10^{-1}$ \\
\hline \multirow[t]{2}{*}{$B(d)$} & $c_{0}=5.6640 \times 10^{-1}$ & $c_{1}=8.5000 \times 10^{-3}$ & $c_{2}=-1.9480 \times 10^{-1}$ & $c_{3}=-6.5320 \times 10^{-1}$ & $c_{4}=-5.462 \times 10^{-1}$ & $c_{5}=-1.7780 \times 10^{-1}$ & $c_{6}=-2.0100 \times 10^{-2}$ \\
\hline & $e_{0}=5.6890 \times 10^{-1}$ & $e_{1}=-9.2300 \times 10^{-2}$ & $e_{2}=4.0200 \times 10^{-2}$ & $e_{3}=1.4523 \times 10^{0}$ & $e_{4}=-2.0780 \times 10^{0}$ & $e_{5}=1.0500 \times 10^{0}$ & $e_{6}=-1.8210 \times 10^{-1}$ \\
\hline
\end{tabular}

$$
B(d)=\left\{\begin{array}{c}
c_{0}+c_{1}\left(\log _{10} d\right)+c_{2}\left(\log _{10} d\right)^{2} \\
+c_{3}\left(\log _{10} d\right)^{3}+c_{4}\left(\log _{10} d\right)^{4} \\
+c_{5}\left(\log _{10} d\right)^{5}+c_{6}\left(\log _{10} d\right)^{6} \\
e_{0}+e_{1}\left(\log _{10} d\right)+e_{2}\left(\log _{10} d\right)^{2} \\
+e_{3}\left(\log _{10} d\right)^{3}+e_{4}\left(\log _{10} d\right)^{4} \\
+e_{5}\left(\log _{10} d\right)^{5}+e_{6}\left(\log _{10} d\right)^{6} \quad d>1.44 \mu \mathrm{m}
\end{array}\right.
$$

A comparison of the new parameterization described by Eqs. (5), (8), and (9) with the $\Lambda_{\text {snow }}$ values from Fig. 5a is shown in Fig. 6a for five different precipitation intensities and the relative error from this comparison is shown in Fig. 6b. Reasonably good agreement was observed for the full range of aerosol particle size and full range of precipitation intensity. The relative error was within $30 \%$ for most aerosol particle sizes, except for the $1-4 \mu \mathrm{m}$ diameter range, for which the error could be as large as $50 \%$. Considering the very large range (i.e., two orders of magnitude or larger) of the existing theoretical $\Lambda_{\text {snow }}$ values (cf., Fig. 4), an uncertainty of $50 \%$ or a factor of 2 in the parameterized $\Lambda_{\text {snow }}$ values should be acceptable.

\section{Discussion}

\subsection{Power-law relationship between $\Lambda$ and $R$}

A power-law relationship between the size-resolved $\Lambda_{\text {rain }}$ or $\Lambda_{\text {snow }}$ parameters and precipitation intensity $R$ for each particle diameter $d$ was identified in Sect. 3 and was used in the development of the new parameterization. The finding of such a power-law relationship is not surprising since many earlier theoretical and experimental studies also suggested the existence of such a relationship, although most of the earlier studies focused on bulk $\Lambda$ instead of size-resolved $\Lambda$ (Mircea and Stefan, 1998; Andronache, 2003; Duhanyan and Roustan, 2011). A brief comparison of the results from the present study with earlier studies in terms of the power-law parameters is provided in Table 9 and presented below.

Early investigations reviewed by McMahon and Denison (1979) and more recent theoretical considerations (e.g., Scott, 1982; Mircea and Stefan, 1998; Andronache,
2003) as well as field and experimental studies (Jylhä, 1991; Okita et al., 1996; Sparmacher et al., 1993) have suggested that the exponent $B$ had values in the range of $0.59-0.94$ for $\Lambda_{\text {rain }}$ and $0.3-1.14$ for $\Lambda_{\text {snow }}$ (see Table 9 and the reviews of Sportisse, 2007, and Duhanyan and Roustan, 2011). The field measurements by Jylhä (1991) and Okita et al. (1996) reported $B$ values of 0.64-0.76. Sparmacher et al. (1993) fitted their experimental $\Lambda$ data from their controlled outdoor study with a power-law relationship and obtained $B(d)$ values of $0.59,0.60,0.94$, and 0.61 for four selected aerosol particle diameters of $0.23,0.46,0.98$, and $2.16 \mu \mathrm{m}$, respectively, for rain scavenging and values of 0.62 , 0.89 , and 1.09 for three selected aerosol particle diameters of $0.46,0.98$, and $1.66 \mu \mathrm{m}$, respectively, for snow scavenging. The $B$ values obtained from theoretical derivations (Scott, 1982; Mircea and Stefan, 1998; Baklanov and Sorensen, 2001; Andronache, 2003; Feng, 2007) ranged from 0.59 to 0.86 for submicron particles and from 0.7 to 0.86 for coarse-mode particles for rain scavenging and from 0.31 to 1.14 for both submicron and for coarse-mode particles for snow scavenging with different habit types of snow crystals. However, the two most recent field studies on snow scavenging (Kyrö et al., 2009; Paramonov et al., 2011) did not identify a clear dependency of $\Lambda_{\text {snow }}$ on $R$. As discussed in Zhang et al. (2013), we speculated that this might be due to the small range of snowfall intensities sampled in these experiments.

The values of $B(d)$ in the present study fall in the range of 0.64-0.91 for rain scavenging (Fig. 2d) and 0.53-0.86 for snow scavenging (Fig. 5d). More specifically, $B(d)$ has values in the ranges $0.64-0.67,0.67-0.72$, and 0.72 0.91 for ultrafine particles $(d<0.01 \mu \mathrm{m})$, mid-range particles $(0.01 \mu \mathrm{m}<d<2 \mu \mathrm{m})$, and large particles $(d>2.0 \mu \mathrm{m})$, respectively, for rain scavenging and values in the ranges $0.66-0.77$, $0.53-0.66$, and $0.58-0.86$, respectively, for the same particle diameter size ranges for snow scavenging. Thus, the results of the present study related to the exponent of the power-law relationship between $\Lambda$ and $R$ are comparable with most of the previous studies for both rain and snow scavenging. 
Table 9. List of below-cloud $\Lambda_{\text {rain }}$ and $\Lambda_{\text {snow }}$ parameterizations from literature expressed as $\Lambda(d, R)=A(d) R^{B(d)}$ (where $\Lambda$ is in units of $\left.\mathrm{s}^{-1}\right)$.

\begin{tabular}{|c|c|c|c|c|c|}
\hline$\Lambda\left(s^{-1}\right)$ & Source & $A(d)\left(\mathrm{s}^{-1}\right)$ & $B(d)$ & $\begin{array}{l}\text { Aerosol diameter } \\
\text { range }(\mu \mathrm{m})\end{array}$ & $\begin{array}{l}\text { Calculation } \\
\text { basis }\end{array}$ \\
\hline \multirow[t]{9}{*}{$\Lambda_{\text {rain }}$} & Jylhä (1991) & $1.0 \times 10^{-4}$ & 0.64 & $0.3-0.9$ & \multirow{2}{*}{$\begin{array}{l}\text { Field } \\
\text { measurements }\end{array}$} \\
\hline & Okita et al. (1996) & $1.0 \times 10^{-4}$ & $0.67-0.76$ & $d>2.0$ & \\
\hline & Sparmacher et al. (1993) & $\begin{array}{l}2.34 \times 10^{-7} \\
3.14 \times 10^{-7} \\
2.56 \times 10^{-7} \\
1.72 \times 10^{-6}\end{array}$ & $\begin{array}{l}0.59 \\
0.60 \\
0.94 \\
0.61\end{array}$ & $\begin{array}{l}0.23 \\
0.46 \\
0.98 \\
2.16 \\
\end{array}$ & $\begin{array}{l}\text { Controlled } \\
\text { experiment }\end{array}$ \\
\hline & Scott (1982) & $3.56 \times 10^{-4}$ & 0.78 & 10.0 & \multirow{6}{*}{$\begin{array}{l}\text { Theoretical } \\
\text { calculation }\end{array}$} \\
\hline & Mircea and Stefan (1998)* & $2.43 \times 10^{-4} E-7.41 \times 10^{-3} E$ & $0.78-0.86$ & Any sizes & \\
\hline & Baklanov and Sorensen (2001) & $8.40 \times 10^{-5}$ & 0.79 & $d<2.8$ & \\
\hline & Andronache (2003) & $\begin{array}{l}2.78 \times 10^{-8}-1.39 \times 10^{-6} \\
6.67 \times 10^{-5}-2.44 \times 10^{-4} \\
\end{array}$ & $\begin{array}{l}0.59-0.61 \\
0.7\end{array}$ & $\begin{array}{l}d<2.0 \\
d>2.0\end{array}$ & \\
\hline & Feng (2007) & $\begin{array}{l}1.19 \times 10^{-6}-2.06 \times 10^{-6} \\
2.36 \times 10^{-7}-3.69 \times 10^{-7} \\
2.11 \times 10^{-4}-3.42 \times 10^{-4} \\
4.92 \times 10^{-4}-5.06 \times 10^{-4}\end{array}$ & $\begin{array}{l}0.62 \\
0.61-0.62 \\
0.79 \\
0.81-0.82 \\
\end{array}$ & $\begin{array}{l}0.001-0.04 \\
0.04-2.5 \\
2.5-16.0 \\
16.0-100 \\
\end{array}$ & \\
\hline & This work & $\begin{array}{l}6.16 \times 10^{-6}-1.17 \times 10^{-4} \\
3.83 \times 10^{-7}-6.16 \times 10^{-6} \\
9.80 \times 10^{-7}-6.70 \times 10^{-5} \\
6.75 \times 10^{-5}-6.89 \times 10^{-4}\end{array}$ & $\begin{array}{l}0.64-0.67 \\
0.67-0.72 \\
0.72-0.91 \\
0.82-0.91\end{array}$ & $\begin{array}{l}0.001-0.01 \\
0.01-2.0 \\
2.0-3.0 \\
3.0-100.0\end{array}$ & \\
\hline \multirow[t]{5}{*}{$\Lambda_{\text {snow }}$} & Sparmacher et al. (1993) & $\begin{array}{l}1.60 \times 10^{-6} \\
8.10 \times 10^{-7} \\
3.49 \times 10^{-6}\end{array}$ & $\begin{array}{l}0.62 \\
0.89 \\
1.09\end{array}$ & $\begin{array}{l}0.46 \\
0.98 \\
1.66\end{array}$ & $\begin{array}{l}\text { Controlled } \\
\text { experiment }\end{array}$ \\
\hline & Mircea and Stefan $(1998)^{*}$ & $2.44 \times 10^{-3} E-3.59 \times 10^{-2} E$ & $0.89-1.14$ & Any sizes & \multirow{4}{*}{$\begin{array}{l}\text { Theoretical } \\
\text { calculation }\end{array}$} \\
\hline & Baklanov and Sorensen (2001) & $8.0 \times 10^{-5}$ & 0.31 & Any sizes & \\
\hline & Scott (1982) & $2.44 \times 10^{-4}$ & 1.0 & 10.0 & \\
\hline & This work & $\begin{array}{l}6.84 \times 10^{-5}-1.80 \times 10^{-3} \\
4.94 \times 10^{-6}-1.19 \times 10^{-4} \\
1.19 \times 10^{-4}-5.13 \times 10^{-4} \\
5.13 \times 10^{-4}-5.50 \times 10^{-3}\end{array}$ & $\begin{array}{l}0.66-0.77 \\
0.53-0.66 \\
0.58-0.61 \\
0.61-0.86\end{array}$ & $\begin{array}{l}0.001-0.01 \\
0.01-2.0 \\
2.0-3.0 \\
3.0-100.0\end{array}$ & \\
\hline
\end{tabular}

* $E$ is the collection efficiency and assumed to be a constant for a given precipitation distribution and aerosols types.

As noted in Sect. 3.1 the parameter $A(d)$ equals $\Lambda(d)$ when $R=1.0 \mathrm{~mm} \mathrm{~h}^{-1}$. Therefore, the values of $A(d)$ should be similar to the upper range of those in the theoretical formulas and lower than those in the field-data-based empirical ones given the design decisions made in the development of the new parameterization. A comparison of $A(d)$ values from the new parameterization with those found in the literature (Table 9) supports this hypothesis.

\subsection{Relative magnitudes of $\Lambda_{\text {rain }}$ and $\Lambda_{\text {snow }}$}

We briefly compared the relative magnitudes of $\Lambda_{\text {rain }}$ and $\Lambda_{\text {snow }}$ in one of our previous studies (Zhang et al., 2013) and concluded that snow scavenging seemed to be more effective than rain scavenging for equivalent precipitation amounts (i.e., liquid water equivalent) based on the median and upperrange theoretical $\Lambda_{\text {rain }}$ and $\Lambda_{\text {snow }}$ values. Since the 90th percentiles of the ensembles of both theoretical $\Lambda_{\text {rain }}$ and $\Lambda_{\text {snow }}$ formulations were used in this study to develop the new parameterizations for $\Lambda_{\text {rain }}$ and $\Lambda_{\text {snow }}$, values of $\Lambda_{\text {snow }}$ from 
(a)

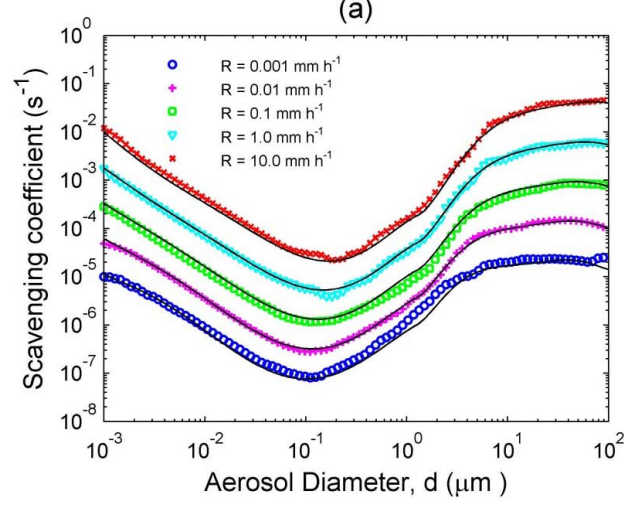

(b)

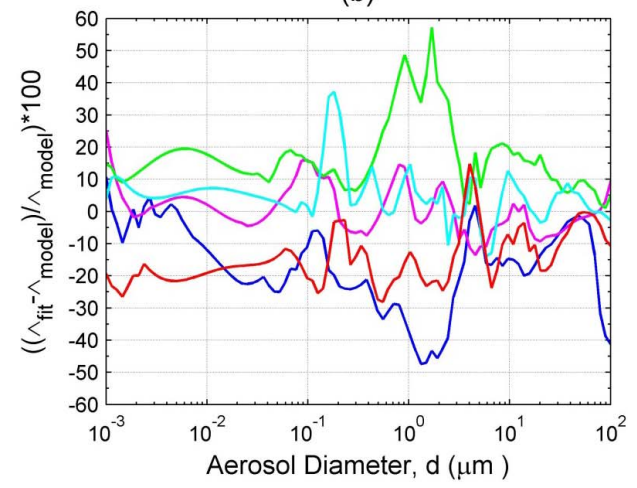

Fig. 6. Same as in Fig. 3 except for $\Lambda_{\text {snow }}$.
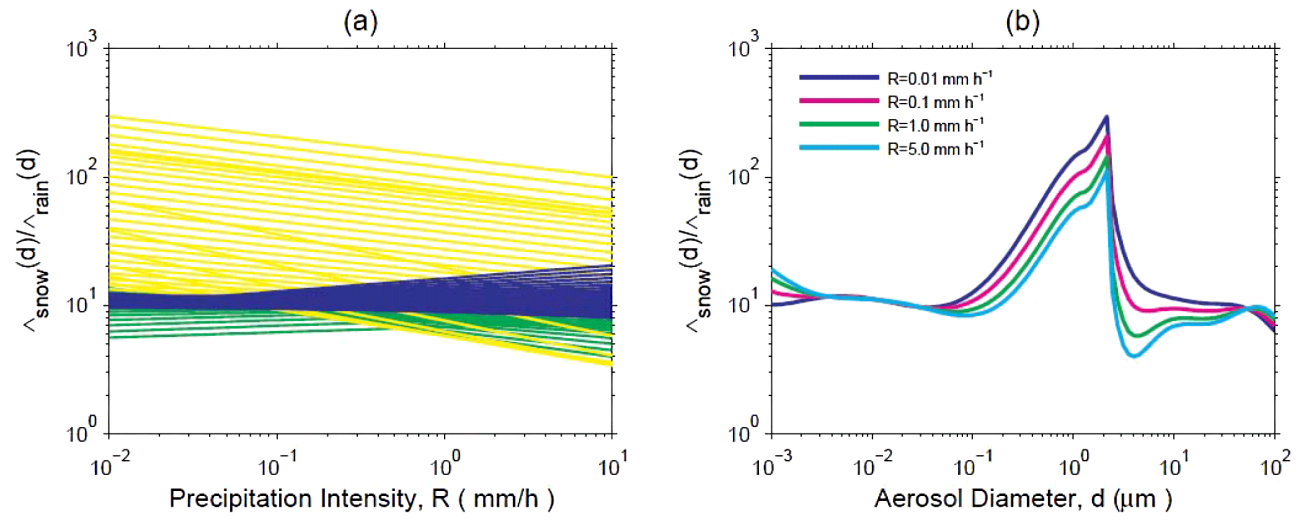

Fig. 7. (a) The ratio of parameterized $\Lambda_{\text {snow }}-\Lambda_{\text {rain }}$ as a function of precipitation intensity $R$ (liquid water equivalent) for 100 aerosol particle diameters (100 lines in total). The groups of blue, yellow, and green lines correspond to aerosol particle diameters $<0.1 \mu \mathrm{m}, 0.1-5.0 \mu \mathrm{m}$, and $>5.0 \mu \mathrm{m}$, respectively; (b) the ratio of parameterized $\Lambda_{\text {snow }}-\Lambda_{\text {rain }}$ as a function of aerosol particle diameter $d$ for four selected values $R$.

the new scheme might be expected to be larger than values of $\Lambda_{\text {rain }}$ from the new scheme for equivalent precipitation intensity. To obtain a quantitative measure of the relative magnitudes of $\Lambda_{\text {rain }}$ and $\Lambda_{\text {snow }}$ for the new parameterization, the ratios of $\Lambda_{\text {snow }}$ to $\Lambda_{\text {rain }}$ as a function of precipitation intensity were calculated for all 100 aerosol particle diameters.

Figure 7a shows that the magnitude of $\Lambda_{\text {snow }}$ is higher than that of $\Lambda_{\text {rain }}$ for the same precipitation intensity by a factor ranging from 3 to 300 , depending on aerosol particle size and precipitation intensity. The ratio of $\Lambda_{\text {snow }}$ to $\Lambda_{\text {rain }}$ is the highest for medium particle sizes (i.e., $0.1<d<5.0 \mu \mathrm{m}$; shown as yellow lines) and is the lowest for coarse and giant particles (e.g., $d>5.0 \mu \mathrm{m}$; shown as green lines). The largest ratios were found for a particle diameter of about $2.0 \mu \mathrm{m}$ for all $R$ values. However, the lowest ratios were found to occur for a particle diameter of $100 \mu \mathrm{m}$ for small $R$ values (lowest green line) and a particle diameter around $4.0 \mu \mathrm{m}$ for large $R$ values (lowest yellow line). The dependence of the $\Lambda_{\text {snow }}$ to $\Lambda_{\text {rain }}$ ratio on particle diameter can be better seen in Fig. $7 \mathrm{~b}$ for selected $R$ values. The ratio decreases with increasing $R$ for medium-size particles (yellow lines in Fig. 7a), increases with increasing $R$ for ultrafine particles (some of the blue lines in Fig. 7a), and only change slightly with increasing $R$ for giant particles (e.g., $d>10 \mu \mathrm{m}$; some of the blue lines in Fig. 7a).

It is possible to offer some explanation of the strong dependence of this ratio on aerosol particle diameter in terms of the physics of precipitation scavenging. Figures $1 \mathrm{~d}$ and $4 \mathrm{~b}$ show that the 90th-percentile $\Lambda$ profiles are qualitatively similar for rain and snow scavenging. However, two significant differences exist between these two profiles. The first difference relates to the value of the aerosol particle diameter at which the minimum $\Lambda$ value occurs. The $\Lambda_{\text {rain }}$ minimum occurs at a particle diameter around $0.4 \mu \mathrm{m}$, whereas the $\Lambda_{\text {snow }}$ minimum occurs at a particle diameter around $0.1 \mu \mathrm{m}$ (which corresponds to a local minimum in Fig. 7). For submicron particles, scavenging is mainly controlled by the interception mechanism and the contribution of this mechanism to scavenging increases with increasing particle diameter (e.g., see Fig. 1 of Wang et al., 2010). For snow scavenging, the increase of $\Lambda_{\text {snow }}$ with particle diameter in this size range is faster than that for rain scavenging due to 
(a)

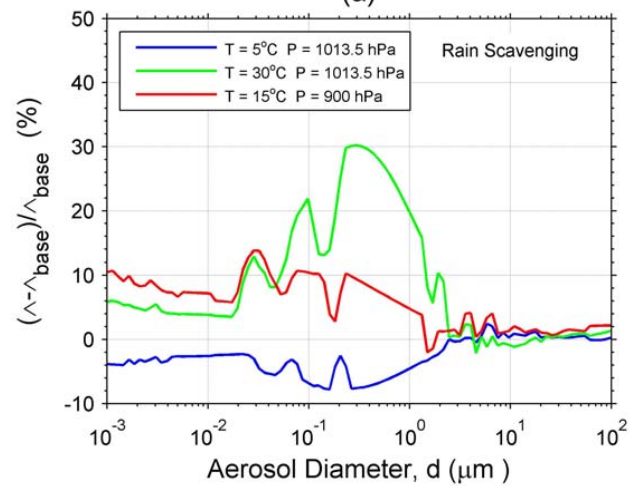

(b)

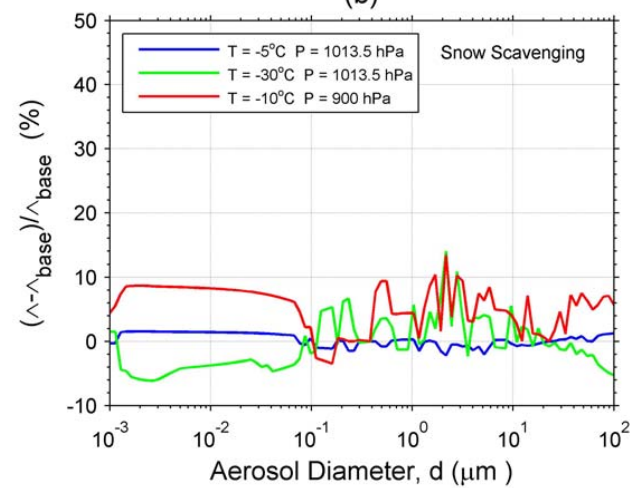

Fig. 8. Percentage differences in $\Lambda$ from the use of different temperature and pressure values for (a) rain and (b) snow scavenging versus base case. A precipitation intensity of $1.0 \mathrm{~mm} \mathrm{~h}^{-1}$ was assumed, and the base case refers to the ambient conditions used to develop the new $\Lambda$ parameterization (i.e., $p=1013.25 \mathrm{hPa} ; T=15^{\circ} \mathrm{C}$ for rain scavenging and $T=-10^{\circ} \mathrm{C}$ for snow scavenging).

the larger cross-sectional areas of snow particles. Thus, the ratio between the snow and rain scavenging coefficients in Fig. 7 increases in the particle diameter range between 0.1 to $1.0 \mu \mathrm{m}$. The second significant difference relates to the abrupt transition of $\Lambda_{\text {rain }}$ from an interception regime to an inertial-impaction regime at a particle diameter of about $2 \mu \mathrm{m}$ (Fig. 1d). For particle diameters larger than $2 \mu \mathrm{m}, \Lambda_{\text {rain }}$ increases more quickly with $d$ than does $\Lambda_{\text {snow }}$. As a result, the $\Lambda_{\text {snow }}$ to $\Lambda_{\text {rain }}$ ratio decreases quickly with increasing $d$ until leveling off for particle diameters close to $10 \mu \mathrm{m}$.

Some previous studies also support the result that snow scavenging is more effective than rain scavenging for equivalent precipitation amounts. Several field studies carried out before the 1980s found that snow scavenging of aerosols was 28 to 50 times more efficient than rain scavenging based on the equivalent water content of the precipitation (Reiter, 1964; Carnuth, 1967; Reiter and Carnuth, 1969; Graedel and Franey, 1975). The average $\Lambda_{\text {snow }}$ value obtained in the controlled outdoor experiment of Sparmacher et al. (1993) was five times higher than the average $\Lambda_{\text {rain }}$ value obtained in similar controlled conditions for two aerosol particle diameters $(0.46$ and $0.98 \mu \mathrm{m})$. Tschiersch (2001) obtained values of $\Lambda_{\text {snow }}$ up to two orders of magnitude higher than $\Lambda_{\text {rain }}$ for particles in the size range of $0.5-3.5 \mu \mathrm{m}$ for low precipitation intensities (water equivalent $<1 \mathrm{~mm} \mathrm{~h}^{-1}$ ). Two recent field studies also claimed that snow is a better scavenger of aerosol particles than rain per equivalent water content (Kyrö et al., 2009; Paramonov et al., 2011). This limited experimental evidence suggests that the new parameterization is qualitatively correct in terms of the relative magnitudes of $\Lambda_{\text {rain }}$ and $\Lambda_{\text {snow }}$, although it may not be quantitatively accurate.

\subsection{Uncertainties in the new $\Lambda$ parameterization related to the choice of ambient atmospheric conditions}

The new parameterization for $\Lambda_{\text {rain }}$ and $\Lambda_{\text {snow }}$ was developed assuming the ambient temperature to be $15^{\circ} \mathrm{C}$ for rain scavenging and $-10^{\circ} \mathrm{C}$ for snow scavenging and the ambient pressure to be $1013.5 \mathrm{hPa}$ for both rain and snow scavenging. Such a choice may introduce uncertainties in $\Lambda$ when the actual ambient atmospheric state differs from the assumed one. To investigate this issue, a set of six sensitivity tests was performed covering the ambient temperature range of $5^{\circ} \mathrm{C}$ to $30^{\circ} \mathrm{C}$ for rain and $-5^{\circ} \mathrm{C}$ to $-30^{\circ} \mathrm{C}$ for snow and for a different ambient pressure $(900 \mathrm{hPa})$ for both rain and snow. Figure 8 shows the percentage difference of the calculated 90th-percentile $\Lambda$ for the above mentioned temperature and pressure values relative to the $\Lambda$ from the new parameterization scheme for different aerosol particle diameters and a precipitation intensity of $1.0 \mathrm{~mm} \mathrm{~h}^{-1}$. The changes in $\Lambda$ values due to different ambient temperature and pressure values are generally within $10 \%$ for all particle sizes for both rain and snow scavenging except for particle diameters from $0.1 \mu \mathrm{m}$ to $2.0 \mu \mathrm{m}$ for rain scavenging, where the differences can reach $30 \%$. Of the four product terms needed to calculate $\Lambda$, only $E\left(d, D_{\mathrm{p}}\right)$ and $V_{D}$ might be impacted by changes in ambient temperature or pressure, and $\Lambda$ is much more sensitive to $E\left(d, D_{\mathrm{p}}\right)$ than to $V_{D}$ (Wang et al., 2010; Zhang et al., 2013). Therefore, uncertainties in $\Lambda$ due to ambient atmospheric condition are likely to arise mainly from the impact of different ambient temperatures and pressures on collection efficiency $E\left(d, D_{\mathrm{p}}\right)$. The larger uncertainty at particle diameters of $0.1-2.0 \mu \mathrm{m}$ for rain scavenging than for snow scavenging is due to the inclusion of thermophoresis and diffusiophoresis collection mechanisms in some of the theoretical formulas, since these two collection mechanisms are sensitive to the ambient atmospheric condition and have a large contribution to particle scavenging at this particular aerosol size range (Wang et al., 2010). Similar uncertainties were also found for other precipitation intensities considered in the present study. 


\section{Conclusions}

The availability of a number of existing theoretical formulas for the size-resolved scavenging coefficient $\Lambda(d)$ requires somewhat arbitrary choices to be made when selecting amongst these schemes and their product terms for implementation in a chemical transport model followed by the coding and run-time solution of often complex algorithms. The new semi-empirical $\Lambda$ parameterization developed in the present study only requires input of precipitation intensity and precipitation type (rain or snow) - two routine output variables in any meteorological model used as a CTM driver. Thus, this new parameterization is readily implementable in any size-resolved aerosol CTM. The new parameterization produces $\Lambda(d)$ values similar to the upper range (90th percentile) of an ensemble of theoretical $\Lambda(d)$ values generated using combinations of all available product-term formulas and is closer than the majority of theoretical $\Lambda(d)$ formulas in terms of comparisons with field-derived $\Lambda(d)$ values. The power-law relationship obtained in this study between $\Lambda(d)$ and precipitation intensity $R$ appears to be comparable to empirical power-law relationships obtained from experimental measurements. The new parameterization produces faster removal of atmospheric aerosol particles by snow scavenging than by rain scavenging for equivalent precipitation intensity, a result in qualitative agreement with evidence from a limited number of field experiments. However, due to the large uncertainties in theoretical $\Lambda$ formulations, the large gaps between theoretical and field-based $\Lambda$ values, and the very limited existing database of field measurements of below-cloud scavenging of size-resolved aerosol particles, especially for snow conditions, more experimental studies are needed at more locations under more climate regimes and for a wider range of aerosol particle sizes to improve our understanding of scavenging processes and to further improve $\Lambda$ formulations. 


\section{Appendix A}

Laakso et al. (2003) empirical parameterization for $\Lambda_{\text {rain }}(d)$

Laakso et al. (2003) suggested a parameterization for $\Lambda_{\text {rain }}(d)$ based on their analysis of six years of field measurements over forests in southern Finland:

$$
\begin{aligned}
\log _{10} \Lambda(d) & =a_{1}+a_{2}\left[\log _{10} d\right]^{-4}+a_{3}\left[\log _{10} d\right]^{-3} \\
& +a_{4}\left[\log _{10} d\right]^{-2}+a_{5}\left[\log _{10} d\right]^{-1}+a_{6} R^{1 / 2}
\end{aligned}
$$

where $d$ is particle diameter (in m), $a_{1}=274.35758, a_{2}=$ $332839.59273, \quad a_{3}=226656.57259, \quad a_{4}=58005.91340$, $a_{5}=6588.38582, a_{6}=0.244984, R$ is rainfall intensity (in $\mathrm{mm} \mathrm{h}^{-1}$ ). The formula is valid only for limited ranges of particle diameters $0.01-0.5 \mu \mathrm{m}$ and for rain intensities $0-20 \mathrm{~mm} \mathrm{~h}^{-1}$.

\section{Appendix B}

\section{Henzing et al. (2006) $\Lambda_{\text {rain }}(d)$ formula fitted from comprehensive numerical simulation}

Henzing et al. (2006) developed a simple $\Lambda_{\text {rain }}$ parameterization that represents below-cloud scavenging coefficients as a function of aerosol particle size and rainfall intensity. The parameterization is a simple three-parameter fit through below-cloud scavenging coefficients calculated at high particle size resolution. The calculations were based on the concept of collection efficiency between polydisperse aerosol particles and raindrop distributions. Specifically, the semi-empirical formula from Slinn (1984) was used for the raindrop-particle collection efficiency. The gamma-function fit of de Wolf (2001) and the empirical formula of Atlas et al. (1973) were applied to represent the raindrop size distribution and the terminal fall velocity, respectively. The parameterization has been applied in a global chemical transport model. The final fitting function has the form

$$
\Lambda(d)=A_{0}\left(e^{A_{1} R^{A_{2}}}-1\right),
$$

where the parameters $A_{0}, A_{1}$ and $A_{2}$ are provided in a table that is available at http://www.knmi.nl/ velthove/wet_ deposition/coefficients.txt.

\section{Appendix C}

\section{The empirical $\Lambda_{\text {snow }}(d)$ formula from Paramonov} et al. (2011)

Paramonov et al. (2011) proposed a $\Lambda_{\text {snow }}$ parameterization from the empirical fit to field measurements from four winters (2006-2010) in an urban environment in Helsinki, Finland:

$\Lambda(d)=10^{a_{1}+a_{2}\left[\log _{10} d\right]^{-2}+a_{3}\left[\log _{10} d\right]^{-1}}+g \cdot(\mathrm{RH})-h$,

where $d$ is particle diameter (in m), $a_{1}=28.0, a_{2}=1550.0$, $a_{3}=456.0, g=0.00015, h=0.00013$, and RH is relative humidity. The formula is only valid for aerosol particles of $0.01-1.0 \mu \mathrm{m}$ in diameter and snowfall intensities of 0.1 $1.2 \mathrm{~mm} \mathrm{~h}^{-1}$ (as liquid water equivalent). Nevertheless, the formula is applicable to snowfall episodes of snowflakes, snow grains, snow crystals, ice pellets, as well as snow mixed with rain.

\section{Appendix D}

The empirical $\Lambda_{\text {snow }}(d)$ formula from Kyrö et al. (2009)

Kyrö et al. (2009) suggested a size-resolved $\Lambda_{\text {snow }}$ parameterization from an empirical fit to four years (2005-2008) of field measurements in a rural background environment in Finland:

$$
\Lambda(d)=10^{a_{1}+a_{2}\left[\log _{10} d\right]^{-2}+a_{3}\left[\log _{10} d\right]^{-1},}
$$

where $d$ is particle diameter (in m), $a_{1}=22.7, a_{2}=1321.0$, and $a_{3}=381.0$. The parameterization applies to snowfall types of light continuous snowfall and snow grains with intensities on the order of $0.1 \mathrm{~mm} \mathrm{~h}^{-1}$ (as liquid water equivalent) and to aerosol particles of $0.01-1.0 \mu \mathrm{m}$ in diameter. 


\section{Appendix E}

\section{Nomenclature}

Table E1. Note that CGS units are used in all of the equations and tables except when otherwise stated because many empirical formulas in Tables 1-7 were developed based on CGS units.

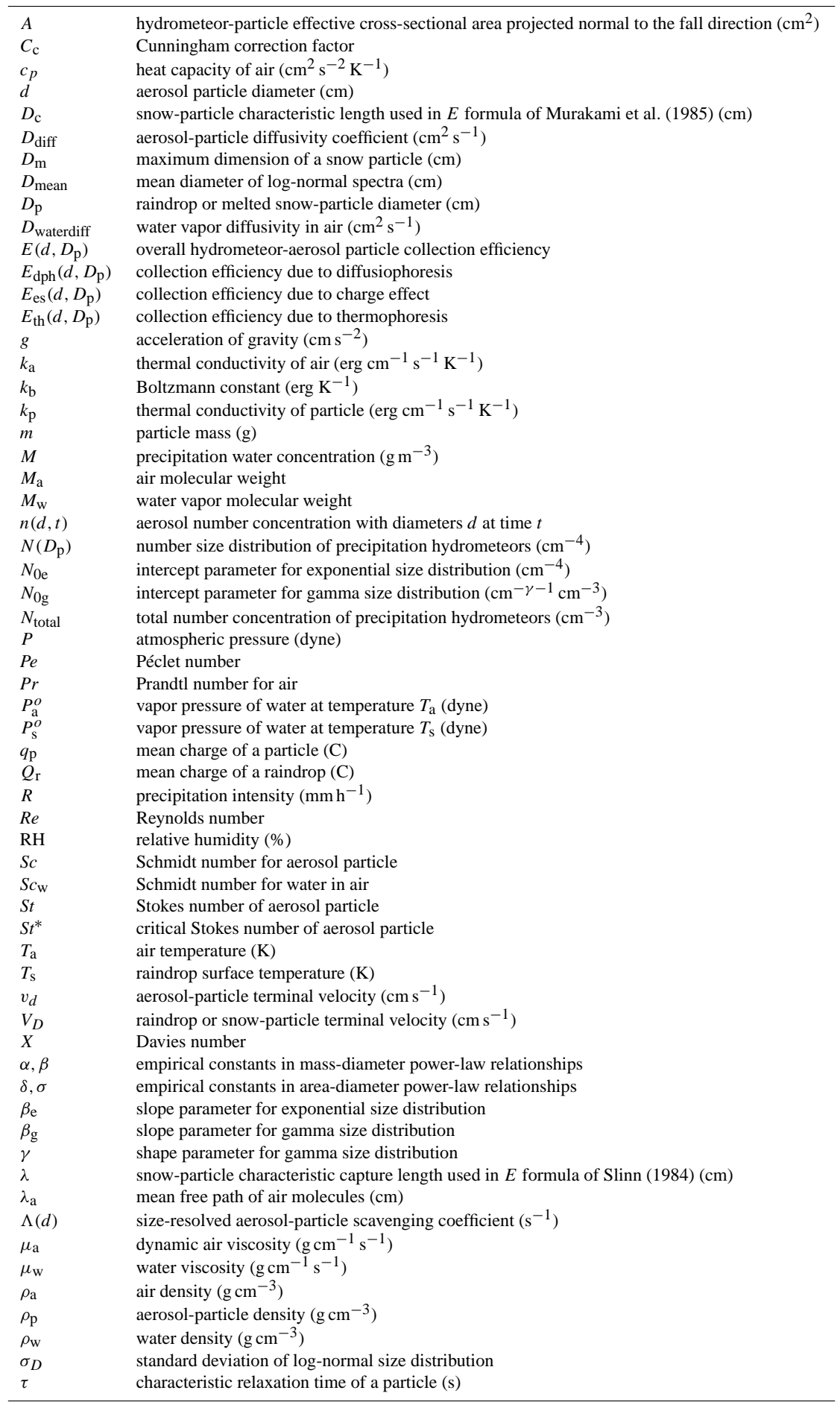


Acknowledgements. We greatly appreciate constructive comments from the editor and anonymous reviewers.

Edited by: O. Boucher

\section{References}

Ackerman, A. S., Toon, O. B., and Hobbs P. V.: A model for particle microphysics, turbulent mixing, and radiative transfer in the stratocumulus-topped marine boundary layer and comparisons with measurements, J. Atmos. Sci., 52, 1204-1236, 1995.

Andronache, C.: Estimated variability of below-cloud aerosol removal by rainfall for observed aerosol size distributions, Atmos. Chem. Phys., 3, 131-143, doi:10.5194/acp-3-131-2003, 2003.

Andronache, C., Grönholm, T., Laakso, L., Phillips, V., and Venäläinen, A.: Scavenging of ultrafine particles by rainfall at a boreal site: observations and model estimations, Atmos. Chem. Phys., 6, 4739-4754, doi:10.5194/acp-6-4739-2006, 2006.

Atlas, D. and Ulbrich, C. W.: Path and area-integrated rainfall measurement by microwave attenuation in the $1-3 \mathrm{~cm}$ band, J. Appl. Meteorol., 16, 1322-1331, 1977.

Atlas, D., Srivastava, R. C., and Sekhon, R. S.: Doppler radar characteristics of precipitation at vertical incidence, Rev. Geophys., $11,1-35,1973$.

Baklanov, A. and Sorensen, J. H.: Parameterisation of radionuclide deposition in atmospheric long-range transport modeling, Phys. Chem. Earth B, 26, 787-799, 2001.

Beard, K. V.: Terminal velocity and shape of cloud and precipitation drops aloft, J. Atmos. Sci., 33, 851-864, 1976.

Best, A. C.: Empirical formulae for the terminal velocity of water drops falling through the atmosphere, Q. J. Roy. Meteorol. Soc., 76, 302-311, 1950.

Brandes, E. A., Zhang, G., and Vivekanandan, J.: Experiments in rainfall estimation with a polarimetric radar in a subtropical environment, J. Appl. Meteorol., 41, 674-685, 2002.

Calvert, S.: Particle control by scrubbing, in: Handbook of air pollution technology, edited by: Calvert, S. and Englund, H. M., Wiley, New York, 215-248, 1984.

Carnuth, W.: Zur Abhängigkeit des Aerosol-Partikel-Spektrum von meteorologischen Vorgängenund Zuständen, Arch. Meteor. Geophys. Bioklim., 16, 321-343, 1967 (in German).

Cerro, C., Codina, B., Bech, J., and Lorente, J.: Modelling raindrop size distribution and $Z(R)$ relations in the Western Mediterranean Area, J. Appl. Meteorol., 36, 1470-1479, 1997.

Chate, D. M.: Study of scavenging of submicron-sized aerosol particles by thunderstorm rain events, Atmos. Environ., 39, 66086619, 2005

Croft, B., Lohmann, U., Martin, R. V., Stier, P., Wurzler, S., Feichter, J., Posselt, R., and Ferrachat, S.: Aerosol size-dependent below-cloud scavenging by rain and snow in the ECHAM5HAM, Atmos. Chem. Phys., 9, 4653-4675, doi:10.5194/acp-94653-2009, 2009.

de Wolf, D. A.: On the Laws-Parsons distribution of raindrop sizes, Radio Sci., 36, 639-642, 2001.

Dick, A. L.: A simple model for air/snow fractionation of aerosol components over the Antarctic Peninsula, J. Atmos. Chem., 11, 179-196, 1990.
Duhanyan, N. and Roustan, Y.: Below-cloud scavenging by rain of atmospheric gases and particulates, Atmos. Environ., 45, 72017217, 2011.

Feingold, G. and Levin, Z.: The lognormal fit to raindrop spectra from frontal convective clouds in Israel, J. Clim. Appl. Meteorol., 25, 1346-1363, 1986.

Feng, J.: A 3-mode parameterization of below-cloud scavenging of aerosols for use in atmospheric dispersion models, Atmos. Environ., 41, 6808-6822, 2007.

Feng, J.: A size-resolved model for below-cloud scavenging of aerosols by snowfall, J. Geophys. Res., 114, D08203, doi:10.1029/2008JD011012, 2009.

Fuchs, N. A.: The mechanics of aerosols, Pergamon, New York, 408 pp., 1964.

Gong, W., Stroud, C., and Zhang, L.: Cloud processing of gases and aerosols in air quality modeling, Atmosphere, 2, 567-616, doi:10.3390/atmos2040567, 2011.

Graedel, T. E. and Franey, J. P.: Field measurements of submicron aerosol washout by snow, Geophys. Res. Lett., 2, 325-328, 1975.

Gunn, K. L. S. and Marshall, J. S.: The distribution with size of aggregate snowflakes, J. Meteorol., 15, 452-461, 1958.

Hall, W. D.: A detailed microphysical model within a two dimensional framework: model description and preliminary results, J. Atmos. Sci., 37, 2486-2507, 1980.

Henzing, J. S., Olivié, D. J. L., and van Velthoven, P. F. J.: A parameterization of size resolved below cloud scavenging of aerosols by rain, Atmos. Chem. Phys., 6, 3363-3375, doi:10.5194/acp-63363-2006, 2006.

Hobbs, P. V., Radke, L. F., Locatelli, J. D., Atkinson, D. G., Robertson, C. E., Weiss, R. R.,Turner, F. M., and Brown, R. R.: Field observations and theoretical studies of clouds and precipitation over the Cascade Mountains and their modifications by artificial seeding (1971-72), Research Report VII, Dept. of Atmos. Sci., University of Washington, Seattle, Washington, USA, available at: http://carg.atmos.washington.edu/sys/research/archive/ cascades_seed_study.pdf (last access: 24 October 2013), 299 pp., 1972.

Jiusto, J. E. and Bosworth, G.: Fall velocity of snow flakes, J. Appl. Meteorol., 10, 1352-1354, 1971.

Joss, J., Thams, J. C., and Waldvogel, A.: The variation of raindrop size distributions at Locarno, in Proc. Internat. Conf. on Cloud Physics, Toronto, 369-373, 1968.

Jung, C. H. and Lee, K. W.: Filtration of fine particles by multiple liquid drop and gas bubble systems, Aerosol Sci. Tech., 29, 389401, 1998.

Jylhä, K.: Empirical scavenging coefficients of radioactive substances released from Chernobyl, Atmos. Environ., 25A, 263270, 1991.

Kessler, E.: On the distribution and continuity of water substance in atmospheric circulations, Meteorol. Monogr., 32, Am. Meteorol. Soc., Boston, USA, 84 pp., 1969.

Khain, A. P. and Pinsky, M. B.: Turbulence effects on the collision kernel, II: Increase of the swept volume of colliding drops, Q. J. Roy. Meteorol. Soc., 123, 1543-1560, 1997.

Kyrö, E.-M., Grönholm, T., Vuollekoski, H., Virkkula, A., Kulmala, M., and Laakso, L.: Snow scavenging of ultrafine particles: Field measurements and parameterization, Boreal Environ. Res., 14, 527-538, 2009 . 
Laakso, L., Grönholm, T., Rannik, U., Kosmale, M., Fiedler, V., Vehkamäki, H., and Kulmala, M.: Ultrafine particle scavenging coefficients calculated from 6 years field measurements, Atmos. Environ., 37, 3605-3613, 2003.

Langleben, M. P.: The terminal velocity of snow aggregates, Q. J. Roy. Meteorol. Soc., 80, 174-181, 1954.

Locatelli, J. D. and Hobbs, P. V.: Fall speeds and masses of solid precipitation particles, J. Geophys. Res., 79, 2185-2197, 1974.

Loosmore, G. A. and Cederwall, R. T.: Precipitation scavenging of atmospheric aerosols for emergency response applications: testing an updated model with new real-time data, Atmos. Environ., 38, 993-1003, 2004.

Maria, S. F. and Russell, L. M.: Organic and inorganic aerosol below-cloud scavenging by suburban New Jersey precipitation, Environ. Sci. Tech., 39, 4793-4800, 2005.

Marshall, J. S. and Palmer, W. M.: The distribution of raindrop with size, J. Meteorol., 5, 165-166, 1948.

Matson, R. J. and Huggins, A. W.: The direct measurement of sizes, shapes and kinematics of falling hailstones, J. Atmos. Sci., 37, 1107-1125, 1980.

McMahon, T. A. and Denison, P. J.: Empirical atmospheric deposition parameters - a survey, Atmos. Environ., 13, 571-585, 1979.

Mircea, M. and Stefan, S.: A theoretical study of the microphysical parameterization of the scavenging coefficient as a function of precipitation type and rate, Atmos. Environ., 32, 2931-2938, 1998.

Mitchell, D. L.: Use of mass- and area-dimensional power laws for determining precipitation particle terminal velocities, J. Atmos. Sci., 53, 1710-1723, 1996.

Mitchell, D. L. and Heymsfield, A. J.: Refinements in the treatment of ice particle terminal velocities, highlighting aggregates, J. Atmos. Sci., 62, 1637-1644, 2005.

Molthan, A. L., Petersen, W. A., Nesbitt, S. W., and Hudak, D.: Evaluating the snow crystal size distribution and density assumptions within a single-moment microphysics scheme, Mon. Weather Rev., 138, 4254-4267, 2010.

Murakami, M., Magono, C., and Kikuchi, K.: Experiments on aerosol scavenging by natural snow crystals, Part 3: The effect of snow crystal charge on collection efficiency, J. Meteorol. Soc. Jpn., 63, 1127-1137, 1985.

Okita, T., Hara, H., and Fukuzaki, N.: Measurements of atmospheric $\mathrm{SO}_{2}$ and $\mathrm{SO}_{4}$, and determination of the wet scavenging of sulfate aerosols for the winter monsoon season over the sea of Japan, Atmos. Environ., 30, 3733-3739, 1996.

Paramonov, M., Grönholm, T., and Virkkula, A.: Below-cloud scavenging of aerosol particles by snow at an urban site in Finland, Boreal Environ. Res., 16, 304-320, 2011.

Park, S. H., Jung, C. H., Jung, K. R., Lee, B. K., and Lee, K. W.: Wet scrubbing of polydisperse aerosols by freely falling droplets, Aerosol Sci., 36, 1444-1458, 2005.

Phillips, C. G. and Kaye, S. R.: The influence of the viscous boundary layer on the critical Stokes number for particle impaction near a stagnation point, J. Aerosol Sci., 30, 709-718, 1999.

Quérel, A.: Particle Scavenging by Rain: A Microphysical Approach, Ph.D. thesis, University Blaise Pascal, ClermontFerrand, France, available at: http://wwwobs.univ-bpclermont.fr/ atmos/fr/Theses/Th_Querel.pdf (last access: 24 October 2013), 2012.
Quérel, A., Monier, M., Flossmann, A. I., Lemaitre, P., and Porcheron, E.: The importance of new collection efficiency values including the effect of rear capture for the belowcloud scavenging of aerosol particles, Atmos. Res., online first, doi:10.1016/j.atmosres.2013.06.008, 2013.

Ranz, W. E. and Wong, J. B.: Impaction of dust and smoke particles, Ind. Eng. Chem., 44, 1371-1381, doi:10.1021/ie50510a050, 1952.

Rasch, P. J., Feichter, J., Law, K., Mahowald, N., Penner, J., Benkovitz, C., Genthon, C., Giannakopoulos, C., Kasibhatla, P., Koch, D., Levy, H., Maki, T., Prather, M., Roberts, D. L., Roelofs, G.-J., Stevenson, D., Stockwell, Z., Taguchi, S., Kritz, M., Chipperfield, M., Baldocchi, D., McMurry, P., Barrie, L., Balkanski, Y., Chatfield, R., Kjellstrom, E., Lawrence, M., Lee, H. N., Lelieveld, J., Noone, K. J., Seinfeld, J., Stenchikov, G., Schwartz, S., Walcek, C., and Williamson, D.: A comparison of scavenging and deposition processes in global models: Results from the WCRP Cambridge Workshop of 1995, Tellus B, 52, 1025-1056, 2000.

Reiter, R.: Felder, Ströme und Aerosole in der unteren Troposphäre, Verlag D. Steinkopff, Darmstadt, 603 pp., 1964 (in German).

Reiter, R. and Carnuth, W.: Washout-Untersuchungen an FalloutPartikeln in der unteren Troposphäre zwischen 700 und $3000 \mathrm{~m}$ NN, Arch. Meteor. Geophy. A, 18, 111-146, 1969.

Scott, B. C.: Theoretical estimates of the scavenging coefficient for soluble aerosol particles as a function of precipitation type, rate and altitude, Atmos. Environ., 16, 1753-1762, 1982.

Seinfeld, J. H. and Pandis, S. N.: Atmospheric chemistry and physics: from air pollution to climate change, Wiley and Sons, New Jersey, 1203 pp., 2006.

Sekhon, K. S. and Srivastava, R. C.: Snow size spectra and radar reflectivity, J. Atmos. Sci., 27, 299-307, 1970.

Sekhon, K. S. and Srivastava, R. C.: Doppler radar observation of drop size in a thunderstorm, J. Atmos. Sci., 28, 983-994, 1971.

Slinn, W. G. N.: Precipitation scavenging, in: Atmospheric Science and Power Production, Chap. 11, edited by: Randerson, D., DOE/TIC-27601, US Department of Energy, Washington, DC, 466-532, 1984.

Solazzo, E., Bianconi, R., Pirovano, G., Matthias, V., Vautard, R., Moran, M. D., Wyat Appel, K., Bessagnet, B., Brandt, J., Christensen, J. H., Chemel, C., Coll, I., Ferreira, J., Forkel, R., Francis, X. V., Grell, G., Grossi, P., Hansen, A. B., Miranda, A. I., Nopmongcol, U., Prank, M., Sartelet, K. N., Schaap, M., Silver, J. D., Sokhi, R. S., Vira, J., Werhahn, J., Wolke, R., Yarwood, G., Zhang, J., Rao, S. T., and Galmarini, S.: Operational model evaluation for particulate matter in Europe and North America in the context of AQMEII, Atmos. Environ., 53, 75-92, 2012.

Sparmacher, H., Fulber, K., and Bonka, H.: Below-cloud scavenging of aerosol particles: particle-bound radionuclides - experimental, Atmos. Environ. A-Gen., 27, 605-618, 1993.

Sportisse, B.: A review of parameterizations for modelling dry deposition and scavenging of radionuclides, Atmos. Environ., 41, 2683-2698, 2007.

Textor, C., Schulz, M., Guibert, S., Kinne, S., Balkanski, Y., Bauer, S., Berntsen, T., Berglen, T., Boucher, O., Chin, M., Dentener, F., Diehl, T., Easter, R., Feichter, H., Fillmore, D., Ghan, S., Ginoux, P., Gong, S., Grini, A., Hendricks, J., Horowitz, L., Huang, P., Isaksen, I., Iversen, I., Kloster, S., Koch, D., Kirkevåg, A., Kristjansson, J. E., Krol, M., Lauer, A., Lamarque, J. F., Liu, X., Mon- 
tanaro, V., Myhre, G., Penner, J., Pitari, G., Reddy, S., Seland, $\varnothing$. , Stier, P., Takemura, T., and Tie, X.: Analysis and quantification of the diversities of aerosol life cycles within AeroCom, Atmos. Chem. Phys., 6, 1777-1813, doi:10.5194/acp-6-1777-2006, 2006.

Tschiersch, J.: Snow deposition of a trace aerosol, J. Aerosol Sci., 32, s195-s196, 2001.

Vohl, O., Mitra, S. K., Wurzler, S. C., Diehl, K., and Pruppacher, H. R.: Collision efficiencies empirically determined from laboratory investigations of collisional growth of small raindrops in a laminar flow field, Atmos. Res., 85, 120-125, 2007.

Wang, X., Zhang, L., and Moran, M. D.: Uncertainty assessment of current size-resolved parameterizations for below-cloud particle scavenging by rain, Atmos. Chem. Phys., 10, 5685-5705, doi:10.5194/acp-10-5685-2010, 2010.

Wang, X., Zhang, L., and Moran, M. D.: On the discrepancies between theoretical and measured below-cloud particle scavenging coefficients for rain - a numerical investigation using a detailed one-dimensional cloud microphysics model, Atmos. Chem. Phys., 11, 11859-11866, doi:10.5194/acp-11-11859-2011, 2011.

Willis, P. T.: Functional fits to some observed drop size distributions and parameterization of rain, J. Atmos. Sci., 41, 1648$1661,1984$.
Willis, P. T. and Tattelman, P.: Drop-size distributions associated with intense rainfall, J. Appl. Meteorol., 28, 3-15, 1989.

Woods, C. P., Stoelinga, M. T., and Locatelli, J. D.: Size spectra of snow particles measured in wintertime precipitation in the Pacific Northwest, J. Atmos. Sci., 65, 189-205, doi:10.1175/2007JAS2243.1, 2008.

Young, K. C.: Microphysical processes in clouds, Oxford University Press, New York, USA, 427 pp., 1993.

Zhang, G., Xue, M., Cao, Q., and Dawson, D.: Diagnosing the intercept parameter for exponential raindrop size distribution based on video disdrometer observations: Model development, J. Appl. Meteorol. Clim., 47, 2983-2992, 2008.

Zhang, L., Wang, X., Moran, M. D., and Feng, J.: Review and uncertainty assessment of size-resolved scavenging coefficient formulations for below-cloud snow scavenging of atmospheric aerosols, Atmos. Chem. Phys., 13, 10005-10025, doi:10.5194/acp-13-10005-2013, 2013.

Zhang, Y.: Online-coupled meteorology and chemistry models: history, current status, and outlook, Atmos. Chem. Phys., 8, 28952932, doi:10.5194/acp-8-2895-2008, 2008. 